\title{
INVESTIGACIONES
}

de HISTORIA ECONÓMICA

2005, invierno, número 1. Pp. 97 a 130

\section{Del diezmo al presupuesto: la financiación de la universidad española (1800-1930)}

\author{
From the tithe to the budget: the Spanish university \\ funding system (1800-1930) \\ RICARDO ROBLEDO HERNÁNDEZ \\ Universidad de Salamanca
}

\begin{abstract}
RESUMEN
En esta investigación se aborda el cambio en

la financiación de la universidad española que, de basarse en la participación en los diezmos, pasó a tener en las tasas académicas su principal sostén. El estudio de la evolución

del ingreso y del gasto de la universidad salmantina permite concretar la visión general y estudiar el impacto del fin del Antiguo

Régimen y del proceso de centralización llevado a cabo por la Hacienda liberal. Por último, se sugiere rebajar el valor explicativo de una deficiente distribución del gasto público en la enseñanza atribuida a una sobreinversión en la educación universitaria.
\end{abstract}

PALABRAS CLAVE: Universidad, Hacienda liberal, Diezmos, Gasto público.

Códigos JEL: N33, N24, I22, H52

\section{ABSTRACT}

The present study deals with the shift of the Spanish university funding system whose main source of income was, above all, the tithe shares, which eventually changed into the academic fees. The study of the evolution of the income and expenditure rates in the University of Salamanca allows us to define exactly the general view and trace the effect caused by the end of the Old Regime and the centralization process carried out by the public finances. Finally, we also suggest reducing the explanatory value of an inadequate distribution of the public expenditure on education, ascribed to an over investment on university education.

KEY WORDS: University, Liberal Government Finance, Tithes, Government Expenditure.

JEL Codes: N33, N24, I22, H52 


\section{Introducción ${ }^{1}$}

"El principio justo y necesario [es] que las enseñanzas superiores sean sostenidas por los mismos que las reciben."

Boletín Oficial de Instrucción Pública (1841), I, p. 31.

$\mathrm{E}$ 1 estudio de la financiación de la universidad española antes de la Guerra Civil ocupa un lugar más bien discreto en la historia económica, como lo testimonia su escasa presencia en los últimos encuentros de historia de las universidades ${ }^{2}$; eso no quiere decir que no existan aportaciones valiosas de quienes se dedican a este campo de investigación o que no se hayan abordado desde la historia económica diversos aspectos de la historia universitaria del siglo XIX, si bien con una intensidad mucho menor que la que ha suscitado, por ejemplo, el indicador del analfabetismo.

En el primer apartado de este trabajo se examina la importancia creciente que tuvo la autofinanciación - rentas tradicionales y tasas académicas- en la universidad liberal. En segundo lugar, el estudio de la evolución del ingreso y del gasto de la universidad salmantina, la principal del país hasta 1808, permite analizar la crisis del Antiguo Régimen y el proceso de centralización financiera llevado a cabo por la Hacienda liberal. Por último, se discute la idea de una deficiente distribución del gasto público en la enseñanza debida a una sobreinversión en la educación universitaria; dado que suelen establecerse comparaciones internacionales, se sugiere la utilización de otros indicadores más complejos que los de las tasas de escolarización.

1 Agradezco las observaciones efectuadas por F. Comín a una primera versión de este texto; también las de L. E. Rodríguez-San Pedro, Juan Luis Polo y las de los asistentes al Seminario de Historia Económica en la Universidad de Zaragoza en junio de 2003; las sugerencias de los evaluadores anónimos han permitido mejorar apreciablemente la estructura del texto, pero el agradecimiento no debe confundirse con la responsabilidad de los errores que pudiera hallar el lector y que competen al autor. José A. Sebastián mejoró la presentación de cuadros y bibliografía. Mientras no se especifique otra cosa, gasto y alumnado universitario se refieren a las llamadas facultades mayores, sin contar lo que hoy denominamos escuelas universitarias. Esta investigación se integra en el Proyecto de Investigación del M. C. y T., BEC 200203704.

2 Congreso Internacional de las Universidades Hispánicas (1998), Rodríguez-San Pedro (ed.) (2000), VV. AA. (2003). 


\section{Marco general: una evaluación de la autofinanciación de la univer- sidad española}

El "nuevo orden de cosas", como solía decirse en el siglo XIX, pudo ser más o menos condescendiente con los intereses que venían del Antiguo Régimen, pero pocas dudas caben respecto de la ruptura con la universidad tradicional. Precedentes siempre pueden hallarse del proceso de centralización, desde el Plan Caballero, que en 1807 extendió a todo el reino el plan de estudios de la Universidad de Salamanca (que incluía por primera vez la enseñanza de la Economía Política), hasta el Plan Calomarde de 1824, donde se detallaron los sueldos de catedráticos o el importe de matrículas; incluso podríamos ironizar con que el primer éxito centralizador lo logró Fernando VII en 1830, con el cierre de todas las universidades. Ahora bien, la reorganización administrativa, académica y financiera de los liberales impuso un giro que no se ha visto rectificado seriamente por ninguna norma posterior, aunque se denomine ley de autonomía universitaria.

Las rentas universitarias del Antiguo Régimen se basaban mayoritariamente en la participación en la producción agraria (diezmos), en rentas de la propiedad rústica, urbana o del capital mobiliario, en juros y vales reales y, en algún caso, —significativo para la Universidad de Oviedo- en tributos indirectos ${ }^{3}$. Cuando se estableció el primer Dictamen de la Comisión de Instrucción Pública, en 1814, se aceptó que las rentas descritas eran suficientes y se acordó que bastaba centralizarlas para financiar adecuadamente la universidad; los créditos presupuestarios sólo tendrían una función subsidiaria.

Las vicisitudes sufridas por los diezmos — extensión del fraude, abolición parcial en 1821 - afectaron gravemente a la financiación universitaria, no quedando otro remedio que recurrir a las tasas en 1822. Desde entonces, las rentas tradicionales (diezmos e ingresos patrimoniales), los derechos académicos y los créditos del presupuesto formaron el trípode donde se asentó la financiación de la universidad, si bien los últimos fueron los menos importantes. Expondré, primero, la relevancia que adquirieron los derechos académicos (matrículas y grados) como fuente de financiación de la universidad; después, me referiré al papel desempeñado por las rentas heredadas del Antiguo Régimen.

En febrero de 1839, cuando se iban dando pasos hacia la centralización de fondos (hacia la Tesorería General del Ministerio de Gobernación, donde estaba entonces Instrucción Pública), se llevó a cabo una información que he resumido en el Cuadro 1. Es un buen punto de partida para observar la evolución de la hacienda universitaria sustentada en las tasas, más aún si se advierte que el valor de las rentas decimales era puramente nominal.

3 La Memoria leída por Argüelles en las Cortes del Trienio (Diario de Sesiones de las Cortes, Apéndice 2, nº 7, p. 93, 4-III-1821) justifica tal generalización aunque cabría hacer diversas matizaciones que, en parte, aparecen en el Cuadro 1. 


\section{CUADRO 1}

RENTAS Y OBLIGACIONES DE LAS UNIVERSIDADES EN 1839 (reales de vellón)

\begin{tabular}{lcccccccc}
\hline & $\begin{array}{c}\text { Diezmos } \\
\%\end{array}$ & $\begin{array}{c}\text { Rentas } \\
\%\end{array}$ & $\begin{array}{c}\text { Censos } \\
\%\end{array}$ & $\begin{array}{c}\text { Otros } \\
\%\end{array}$ & $\begin{array}{c}\text { Tasas } \\
\%\end{array}$ & $\begin{array}{c}\text { Total } \\
\text { rentas (rs.) }\end{array}$ & $\begin{array}{c}\text { Obliga- } \\
\text { ciones }\end{array}$ & Saldo \\
\hline Alcalá & 59 & 7 & - & & 34 & 268.783 & 277.360 & -8.577 \\
Sevilla & 11 & 4 & 0 & & 85 & 141.688 & 153.694 & -12.006 \\
Valladolid & 32 & 3 & 5 & 6 & 54 & 259.516 & 212.011 & 47.505 \\
Valencia & - & 3 & - & 1 & 96 & 108.056 & 167.299 & -59.243 \\
Oviedo & - & 3 & 1 & 67 & 29 & 140.493 & 142.763 & -2.270 \\
Granada & 3 & 0 & 6 & - & 91 & 159.399 & 250.206 & -90.807 \\
Salamanca & 75 & 7 & 3 & 2 & 13 & 406.287 & 439.544 & -33.257 \\
\hline Total & $\mathbf{3 8}$ & $\mathbf{5}$ & $\mathbf{2}$ & $\mathbf{7}$ & $\mathbf{4 8}$ & $\mathbf{1 . 4 8 4 . 2 2 2}$ & $\mathbf{1 . 6 4 2 . 8 7 7}$ & $-\mathbf{- 1 5 8 . 6 5 5}$ \\
\hline
\end{tabular}

Fuente: Elaboración a partir de Boletín Oficial de Instrucción Pública (1841).

Faltan algunas universidades, por ejemplo la de Santiago, pero la investigación de Martínez Rodríguez (1981) sobre ésta permite apreciar, también, cómo se fueron abriendo las "tijeras" entre rentas tradicionales y tasas académicas, en lo que pudo ser un esquema general que, con ritmos distintos, fue rompiendo la tradición de gratuidad de la enseñanza universitaria del Antiguo Régimen (Gráfico 1). En conjunto, las tasas por matrícula y lo recaudado en concepto de títulos académicos iban rellenando el hueco dejado por la abolición del diezmo.

Los derechos de matrícula eran prácticamente simbólicos en el Antiguo Régimen (a principios del siglo XVIII, el nuevo arancel de derechos sólo exigía medio real de vellón por matricularse en la Universidad de Salamanca), mientras que, en 1875, tan sólo el pago de la matrícula de una asignatura de Medicina suponía 15 pesetas (60 reales) ${ }^{4}$. De no pagar prácticamente nada, el universitario español pasó a tener que abonar, en 1837, de 160 a 200 reales, según el tipo de facultad, es decir, 8 ó 10 veces más que en 1824, cuando ya se había roto la gratuidad (Cuadro 2); esta espectacular

4 El primer dato en Polo (1995), el segundo, en Archivo de la Universidad de Salamanca, (AUS, en adelante), L. R. 303. Otra cosa es el elevado gasto que suponía la consecución de grados de licenciado o doctorado. 


\section{GRÁFICO 1}

COMPOSICIÓN DE LOS INGRESOS DE LA UNIVERSIDAD DE SANTIAGO, 1823-1844

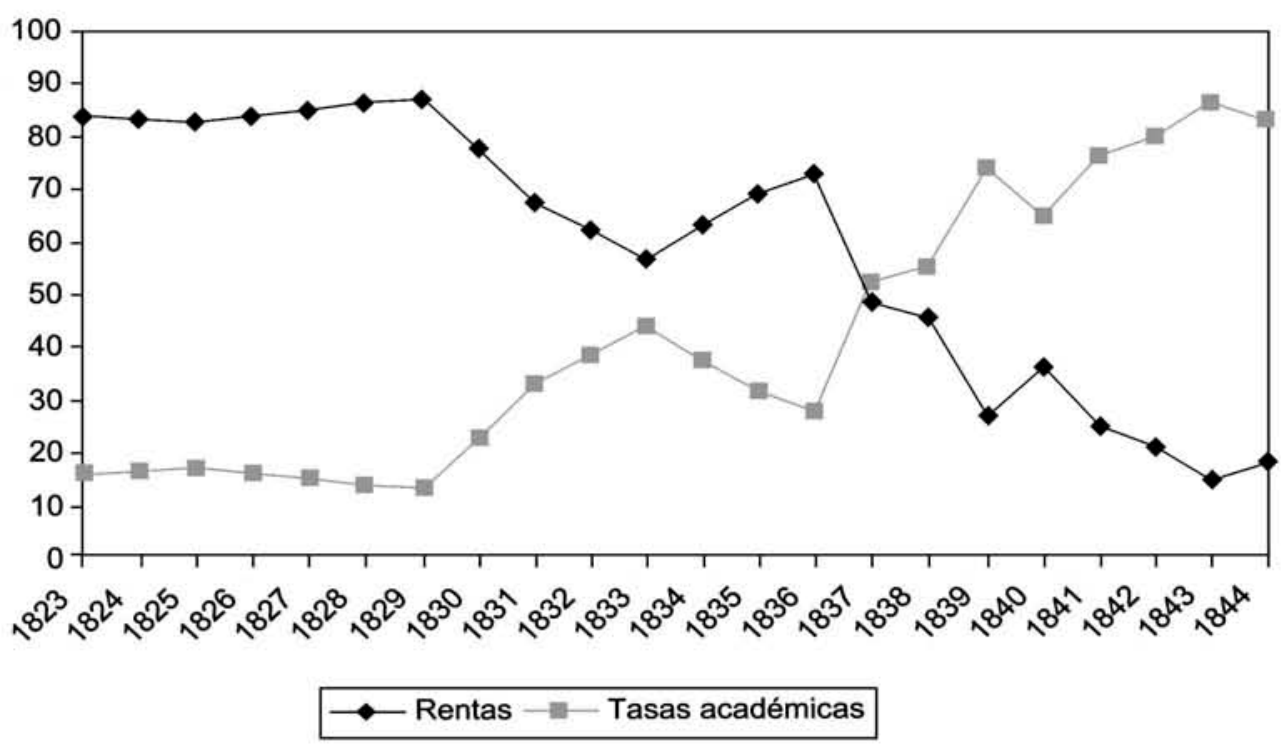

Fuente: Martinez Rodríguez (1981), pp. 32-36.

subida no se detuvo en años posteriores, de modo que en términos reales se multiplicó su importe por 2,3 entre 1838 y 1877 . Hacia 1860, con 300 reales se podía costear la compra de pan para una persona adulta durante la mayor parte del año ${ }^{5}$. Si ya era elevado este coste, mayor lo era el de oportunidad, dadas las pérdidas de ingresos por dejar de trabajar durante varios años. Además, como es comprensible, el pago de estos derechos era sólo una pequeña parte del gasto total del alumno que tuviera que desplazarse a estudiar; durante el Antiguo Régimen, los colegios mayores y menores financiaban este tipo de gastos a sus residentes, pero, desde 1835, ya no quedaban colegios, ni tampoco conventos que a sus puertas alimentaran a los estudiantes de sopa. Al gasto que suponía matrícula y estancia había que sumar lo que importaba la consecución del grado de licenciado; su cuantía de 3.000 reales venía a suponer la cuarta parte del sueldo anual de la mayoría de catedráticos, tal como se fijó en el Plan de 1845.

5 Serían 330 días calculando un consumo de 700 gramos diarios. Los precios y la estimación de consumo en Garrabou, Tello y Roca (1999), p. 451. 


\section{CUADRO 2}

DERECHOS ACADÉMICOS, MATRÍCULA Y GRADOS (reales de vellón)

\begin{tabular}{lccccc}
\hline & $(\mathbf{1})$ & $(\mathbf{2})$ & $\mathbf{( 3 )}$ & Bachiller & Licenciado \\
\hline $\mathbf{1 8 2 4}$ & 20 & & & 300 & 3.000 \\
$\mathbf{1 8 3 8}$ & 160 & 186 & 100 & 400 & 3.000 \\
$\mathbf{1 8 5 7}$ & 280 & 317 & 171 & 400 & 3.000 \\
$\mathbf{1 8 6 7}$ & 320 & 381 & 205 & 400 & 3.000 \\
$\mathbf{1 8 7 7}$ & $420^{6}$ & 442 & 237 & & \\
\hline
\end{tabular}

(1) Matrícula, reales de vellón corrientes.

(2) Pesetas de 1913 expresadas en reales de vellón, índice de precios de Maluquer (2004), 1913=100

(3) Índice de (2), 1838=100.

Fuente: Álvarez Morales (1974), Peset (1974) Martínez Alcubilla (1887) y Colección de los Decretos y Órdenes.

En resumen, no estaba la universidad en el horizonte de los menesterosos, ni posiblemente en el de buena parte de las clases medias. Sin conventos o facultades de Teología donde formar la élite para la burocracia eclesiástica, el alumnado, aparte de más acomodado, se hizo forzosamente laico; como al mismo tiempo el censo electoral excluía a los menos pudientes, cobraron fuerza las críticas contra una oligarquía "monopolizadora de las carreras llamadas liberales y científicas"

Los liberales del trienio tuvieron mala conciencia cuando decidieron acabar, todavía tímidamente, con la gratuidad de la enseñanza universitaria ${ }^{8}$, pero para llenar el vacío que dejaba el impago de los diezmos, no se les ocurrió, por ejemplo, desviar partidas presupuestarias de otros ministerios en favor de la Instrucción Pública. Se apoyaron en motivos presupuestarios para elevar los derechos de matrícula; después, el déficit no se contuvo, pero el encarecimiento de la matrícula se utilizó para frenar el acceso a las aulas.

6 Es una estimación suponiendo el pago de los derechos de matrícula de cinco asignaturas y los de examen de tres, fijados respectivamente en 15 y 10 pesetas, por R. D. 10-VIII-1877, Martínez Alcubilla (1887), tomo 6, p. 407.

7 Expresión de Fernando Garrido citada en Álvarez Morales (1974), p. 480. Los seminarios se encargaron de dar cobijo a los hijos de las clases menos acomodadas.

8 La Comisión tomó la decisión "con mucho dolor, pero lo hace obligada por la imperiosa ley de la necesidad, pues no encuentra recursos para llevar a cabo el establecimiento de la enseñanza, y peor sería carecer de ella que hacerla un poco más costosa", Diario de Sesiones de las Cortes, 20-VI-1822, p. 2.240. 
La primera formulación clara del principio de restringir la enseñanza gratuita se encuentra en el Plan del Duque de Rivas de 1836, con su analogía de la pirámide en cuya cúspide se sitúan los que pueden costearse la universidad.

"La [obligación] de gratuidad del gobierno es como una pirámide, que, empezando en una ancha base, formada por los menesterosos, disminuye a proporción que disminuye su altura y creciendo la riqueza de los particulares", Gil de Zárate (1855), p. 164.

Sin duda, los liberales fueron eficientes en crear barreras de entrada a la enseñanza universitaria, lo que provocó rechazo en los claustros y en la calle 9 . Como refleja el Cuadro 9, el alumnado universitario se redujo sustancialmente en la primera mitad del siglo XIX: si en 1797 uno de cada 60 jóvenes de 20-24 años estaba en la universidad (lo que estaría relacionado con la fuerte representación de los eclesiásticos en el Antiguo Régimen), en 1857 dicha proporción había pasado a uno de cada 160.

El segundo aspecto a tener en cuenta en la autofinanciación es el proceso de absorción de las rentas antiguas por la centralización liberal. Bien fuera el Banco Español de San Fernando, como banquero del gobierno hasta 1848, el encargado de percibir las rentas que pertenecieran al Estado y satisfacer las obligaciones de éste, o la Dirección General de Contabilidad, dependiente del Ministerio de Hacienda, la filosofía que se impuso fue la absorción de los ingresos y rentas de las universidades por la Hacienda Pública, correlato de la centralización académica y administrativa que exigía el estado liberal ${ }^{10}$. Recordemos que hasta la desamortización de Madoz subsistía en buena medida la mayor parte del patrimonio de las universidades y colegios, cuyas rentas, aparte de otros menesteres, alimentaban el presupuesto estatal de Instrucción Pública, de donde se distribuía proporcionalmente según lo presupuestado por cada universidad. Como ocurre ahora, la retribución de cada profesor se ajustaba a la escala retributiva que fijaba el Estado. Por otra parte, rectores y decanos se encargaban de distribuir los gastos de mantenimiento de cada establecimiento, que casi siempre estuvieron bajo mínimos. De "repúblicas enseñantes" con autonomía financiera, las universidades se habían convertido en meras depositarías del Ministerio de Hacienda, si nos atenemos a la intervención del Estado en sus caudales.

9 Sobre las protestas y amago de boicot de los alumnos de la Universidad de Valencia, Baldó y Mir (2000), p. 19. Sobre disturbios estudiantiles y enfrentamientos con la policía en Madrid, hacia 1850, por la elevación de matrículas, Peset (1974), p. 379.

10 Hasta 1845 , los claustros disponían del importe de los grados para propinas de los profesores. El detalle de las distintas reformas por las que se fue consolidando y centralizando la hacienda liberal, en Gil de Zárate (1855), pp. 211-234, Peset (1974), pp. 729-751, Álvarez Morales (1974), pp. 247-264, y, especialmente, Dávila (1992). 


\section{CUADRO 3}

PRESUPUESTO DE INSTRUCCIÓN PÚBLICA, 1842-54 (reales de vellón) ${ }^{11}$

\begin{tabular}{ccccccc}
\hline & $\begin{array}{c}\text { Gastos } \\
\mathbf{( 1 )}\end{array}$ & $\begin{array}{c}\text { Ingresos } \\
\mathbf{( 2 )}\end{array}$ & $\mathbf{( 2 ) / ( \mathbf { 1 } ) \%}$ & $\begin{array}{c}\text { Universidades } \\
\text { Gastos (3) }\end{array}$ & $\begin{array}{c}\text { Universidades } \\
\text { Ingresos (4) }\end{array}$ & $\mathbf{( 4 ) / ( 3 ) \%}$ \\
\hline $\mathbf{1 8 4 2}$ & 10.824 .704 & 5.479 .354 & 51 & 6.225 .940 & 5.162 .184 & 83 \\
$\mathbf{1 8 4 3}$ & 9.722 .383 & 5.602 .828 & 58 & 5.055 .911 & 5.286 .288 & 105 \\
$\mathbf{1 8 4 5}$ & 10.053 .094 & 6.652 .577 & 66 & 6.535 .566 & - & - \\
$\mathbf{1 8 4 9}$ & 16.096 .186 & 8.940 .000 & 56 & 11.003 .728 & - & - \\
$\mathbf{1 8 5 0}$ & 15.349 .974 & 8.841 .000 & 58 & 9.765 .528 & - & - \\
$\mathbf{1 8 5 1}$ & 15.273 .583 & 9.500 .000 & 62 & 8.254 .488 & {$[7.789 .562]$} & 94 \\
$\mathbf{1 8 5 3}$ & 12.352 .748 & 10.525 .000 & 85 & 8.454 .118 & {$[8.220 .000]$} & 97 \\
$\mathbf{1 8 5 4}$ & 12.612 .063 & 10.525 .000 & 83 & 8.793 .258 & {$[8.220 .000]$} & 93 \\
\hline
\end{tabular}

Fuentes: Elaboración según Diario de Sesiones de las Cortes, 4-VII-1842, 15-XI-1842, 17-XII-1845, Colección de las leyes, decretos..., (1849-51), y Presupuestos, 1853, 1854.

El proceso de centralización fue un peldaño más en la construcción del Estado liberal y se inserta claramente en la reforma de la Hacienda de 1845, que absorbió los ingresos de las otras haciendas (laicas o eclesiásticas) ${ }^{12}$. Como durante 1841-1855 se formó un presupuesto particular de Instrucción Pública donde estaban desglosados los ingresos, se puede demostrar que el gasto presupuestado para las distintas secciones de Instrucción Pública podía autofinanciarse en un 50-85 por 100 gracias a tasas académicas y rentas del Antiguo Régimen (Cuadro 3). En algún año, incluso, el ramo de Instrucción Pública llegó a financiar otras partidas del presupuesto; los 6 millones de reales que en 1847 ingresó el Sr. Salamanca en el Tesoro es el caso más

11 En los años 1842-45, he tenido en cuenta los ingresos y los gastos de la Escuela de Veterinaria y del Colegio de Farmacia; en los años siguientes, se consideran gastos de Universidad los que figuran en concepto de Personal y Material de la misma. Los ingresos de Instrucción Pública de 1849-53 son ingresos líquidos. El dato de ingresos de 1851 es una estimación basada en Gil de Zárate (1855), p. 232. Los de 1853-54 son “Derechos de matrícula y grados" de I. Pública, sin especificar, tal como aparecen en Presupuestos (...) de 1854, p. 49. No toda la enseñanza estaba en Instrucción Pública, pues Fomento se hizo cargo hasta 1855 de las escuelas de ingenieros.

12 Como ocurrió con obras pías, fundaciones y otras entidades tuteladas por la iglesia, cuyos ingresos acabaron absorbidos por la Hacienda para financiar la Beneficencia, Comín (1996), p. 257. 
conocido $^{13}$. A partir de 1855, las rentas de instituciones educativas disminuyeron con la desamortización de Madoz, pero los ingresos por venta de bienes de Instrucción Pública, sumados a los que procedían de las tasas académicas, debieron seguir permitiendo un alto grado de autofinanciamiento; de hecho, tan sólo entre 1859 y 1867 se vendieron bienes de este ramo por valor de unos 104 millones de reales ${ }^{14}$. Los datos fragmentarios relativos a ingresos de universidades (última columna del Cuadro 3) demuestran cómo éstas le salían casi gratis al Estado liberal en aquellos años ${ }^{15}$.

No hay mejor testimonio que el del responsable de llevar a cabo la centralización de los fondos de la Instrucción Pública. Gil de Zárate, que había demostrado que los gastos en Instrucción Pública no habían crecido durante su mandato tanto como se le recriminaba, se lamentaba del vigente "espíritu de economía y mezquindad" con dos argumentos contundentes. Uno, el error de considerar la enseñanza como una fuente de renta, como pretendía Bravo Murillo, dándose la paradoja de que, al tiempo que se elevaban los derechos de matrícula, disminuían los gastos de Instrucción Pública, lo que se advierte desde 1849 en el Cuadro 3. Y dos, el desigual trato recibido respecto de la enseñanza eclesiástica, pues tan sólo el gasto en los seminarios, más de 5 millones de reales, equivalía al déficit de toda la Instrucción Pública que el Estado tenía que financiar (Gil de Zárate, 1855, pp. 232-234). No menos llamativo resulta extender la comparación al presupuesto del Arzobispado de Toledo (8.781.387 reales en 1851), similar al de la universidad, o a los gastos fijados para la Casa Real en 1845 (43,5 millones), siete veces más que los de la enseñanza universitaria ${ }^{16}$.

La Ley Moyano de 1857, que de algún modo cerraba el ciclo de la reforma universitaria liberal, consolidó el raquitismo del gasto público al organizar una Universidad Central con todas las titulaciones y el doctorado y otras nueve "de provincias", que no dejaban de ser de segunda categoría. El cambio institucional más importante vino con la Revolución de 1868, al permitir que ayuntamientos y diputaciones financiaran totalmente la enseñanza superior, Se rompía así la división tripartita de la financiación de la Instrucción Pública — según se ampliaba el ámbito de las competencias fiscales (municipio, provincia, Estado), subía el nivel de financiación de la

13 Gil de Zárate (1855), p. 229, La Fuente (1889). Teniendo en cuenta ese ingreso y lo que había dejado de percibir, Gil de Zárate evaluaba en 12 millones de reales las pérdidas de la Instrucción Pública de 1847 a 1852. Hasta julio de 1847, la Junta de Centralización pagaba el gasto de los establecimientos, pero a partir de entonces el ramo de Instrucción Pública pasó a depender directamente del Tesoro.

14 Simón Segura (1973), pp. 250-251. En 1861, sólo los ingresos por venta de bienes de instrucción pública inferior financiarían, según el Presupuesto Extraordinario, el 72 por 100 del gasto en Instrucción Pública (Colección Legislativa de España [1861], Tomo LXXV, p. 71); hasta 1895 restaban por vender unos 31 millones de reales. Todavía en el presupuesto de 1891-92 se ingresaron en el Tesoro 5,5 millones de reales procedentes de bienes de universidades y establecimientos de segunda enseñanza, Groizard (1899), p. 23.

15 Dado el encarecimiento de las matrículas, Gil de Zárate (1855), p. 233, estimaba que la Universidad había tenido superávit en 1852.

16 Colección Legislativa de España $(1845,1851)$. 
instrucción pública- y disminuía, por consiguiente, el proceso de centralización a tono con otras medidas de libertad y de descentralización que dictaba la llamada escuela economista... Nacían así las llamadas facultades libres (para distinguirlas de las oficiales, que tenían financiación estatal), permitiendo a diputaciones o ayuntamientos de las provincias en que hubiera universidades costear las enseñanzas de facultades o asignaturas no comprendidas en su organización (Decreto 14-I-1869). Precisemos que se trataba de facultades de titularidad pública, lo único que variaba era la financiación a cargo de las haciendas locales y una remuneración inferior del profesorado hasta 1900. Gracias a esto, universidades como las de Salamanca, Zaragoza, Sevilla y Oviedo pudieron mantener, en más de un caso hasta principios del siglo XX, facultades de Ciencias o de Medicina.

\section{Evolución de la hacienda universitaria salmantina}

A continuación, tras presentar el marco general, analizaré el impacto de la crisis del Antiguo Régimen sobre la Universidad de Salamanca. En segundo lugar, consideraré el declive de su hacienda tradicional, que puso en peligro su permanencia, y el desarrollo de un sistema mixto de financiación -Estado, haciendas locales- que corrigió la tendencia decadente de la universidad salmantina, "la primera de estos Reynos" como se reconocía a finales del siglo XVIII.

\subsection{El derrumbe del ingreso tradicional en la crisis del Antiguo Régimen ${ }^{17}$}

La financiación de la Universidad de Salamanca descansaba básicamente sobre una exacción de tipo señorial: la participación en los diezmos eclesiásticos (las tercias) de varios núcleos de las diócesis salmantina y vallisoletana; de ahí provenía, durante la segunda mitad del siglo XVIII, el 70-80 por 100 de sus ingresos. Se trataba de un sistema consolidado desde la Edad Media, que condicionó durante cinco siglos la existencia de la institución hasta hacerlo parecer insustituible, incluso cuando ya los diezmos estaban abolidos. Las rentas del capital mobiliario (censos) y del patrimonio rústico y urbano, que completaban el recibo, tenían a fines del Setecientos más importancia que en el pasado, suponiendo a veces un tercio de aquél.

La tendencia descendente del ingreso de la institución se puede evaluar en su reducción a una quinta parte $-\mathrm{o}$, en términos reales, a algo más de un tercio-, si

\footnotetext{
17 Para mayor detalle, Robledo (2002), pp. 205-237, donde se comentan aspectos políticos que no dejaron de
} tener trascendencia económica. 


\section{GRÁFICO 2}

SUELDOS DE PROFESORES Y MINISTROS, 1800-01/1839-40 (reales de vellón)

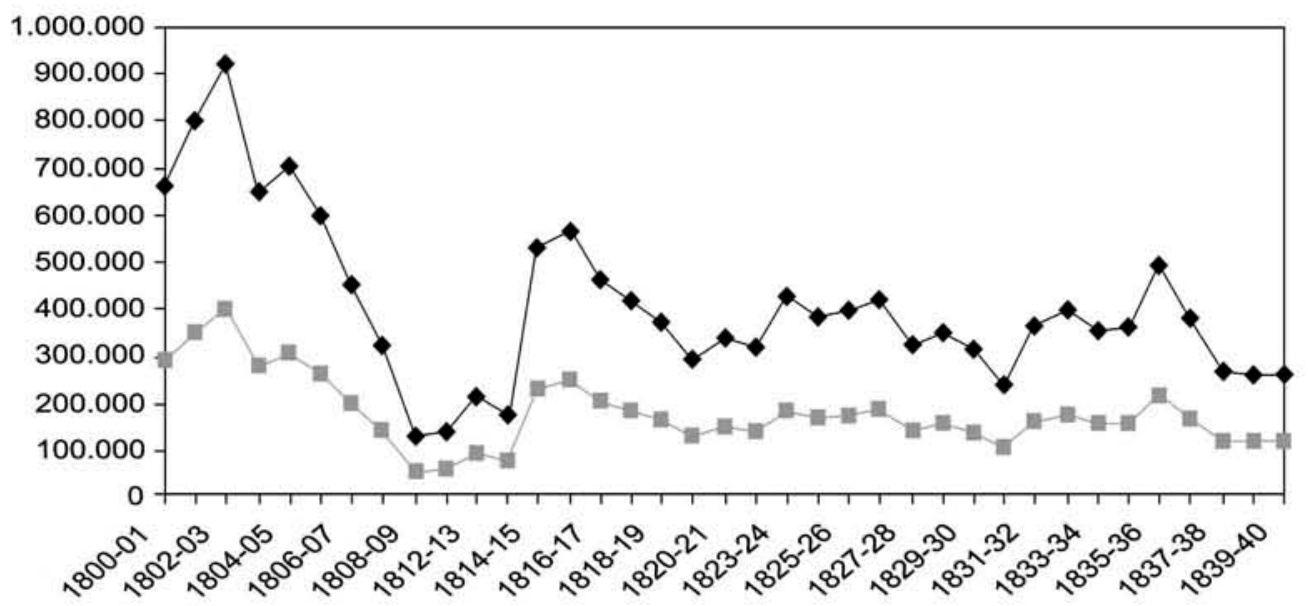

Fuente: Robledo (2002), p. 208.

comparamos los primeros años del siglo XIX y 1837-40. En el Gráfico 2 se expone un indicador bien preciso, la evolución del gasto en sueldos y salarios, que, al igual que hoy (el denominado "capítulo 1"), consumía la mayor parte del presupuesto. Según se advierte en el gráfico, dicho renglón pasó de cerca de 800.000 reales, el promedio anual en 1800-02, a unos 260.000 en el trienio 1838-40, lo que supone una contracción, en cuarenta años, del 70 por 100 en términos corrientes y un poco menos en términos reales. La abrupta caída de los sueldos antes de 1808 no vino acompañada de una disminución del número de profesores; en este sentido conviene precisar un indicador que mide mejor que ningún otro la pérdida del poder adquisitivo: el valor del florín (moneda de cuenta que medía la remuneración de las distintas cátedras) se evaluó en 125 reales en los últimos años del siglo XVIII, situándose en 50-60 reales en $1806-1807^{18}$.

No son muy distintas las causas que provocaron el declive de la hacienda universitaria salmantina de las que influyeron en el descenso de los ingresos de otras haciendas en la crisis del Antiguo Régimen. La escasa rigurosidad en el pago de los diezmos debe situarse como causa principal, pues la participación de la Universidad 
en la masa decimal solía constituir cerca del 80 por 100 de sus ingresos. Otras causas de índole política, o más relacionadas con la coyuntura económica, como la crisis posterior a las guerras napoleónicas, fueron erosionando los ingresos igual que los de los señores. La diferencia con las economías señoriales residía en que la Universidad no potenciaba sus males gastando más de la cuenta y endeudándose onerosamente (Robledo, 1991); el mal estaba en la tendencia decreciente del ingreso -el "cargo" - más que en los gastos — la "data"-, aunque aquí haya que matizar la incidencia de alguna partida, como la de las contribuciones, dada la presión fiscal que se vio obligada a introducir la monarquía absoluta ${ }^{19}$.

Como era previsible, la tendencia decreciente del tributo decimal, iniciada ya antes de 1808, se acentuó gravemente durante la Guerra de Independencia. Más que pormenorizar el desplome de las rentas, conviene hacer breve mención al modo de desviar las exacciones que exigían invasores y patriotas. Si los pueblos, ante circunstancias similares, estaban acudiendo a la venta de las tierras concejiles, el claustro recurrió, como el cabildo salmantino o los señores, a su reserva patrimonial, empezando por enajenar los bienes que tenían mayor grado de liquidez o más gastos de mantenimiento. De este modo, se alienó parte del patrimonio artístico, mobiliario e inmobiliario, para pasar mal que bien los años de la guerra: se vendió plata de la capilla, se repartieron vales reales entre profesores y empleados, pero sobre todo se enajenó el patrimonio urbano (de unas cien casas sólo quedaron ocho), y algunas fincas rústicas.

$\mathrm{Al}$ acabar la guerra, males de antaño como "los fraudes de los labradores" se incrementaron con el fenómeno de las nuevas roturaciones. Un testimonio de 1815 precisa bien la secuencia de los hechos:

"Las causas de la decadencia del decimal son la imposición del Real noveno, los diezmos de exentos que hasta ahora ha llevado la Real Hacienda, el deplorable estado de la agricultura por las resultas de tan desastrosa guerra, y los diezmos novales, que han pretendido exclusivamente para sí los Párrocos, producidos de las muchas tierras concejiles y comunes, que se han roturado de nuevo, abandonando la labor de las tierras antiguas, que producían para los demás partícipes de diezmos, y principalmente los fraudes de los Labradores en el modo de diezmar. En el año de 1813 tuvo además la rebaja de un 30 por 100 decimal, y la contribución directa, impuestas por el Gobierno. Las propiedades han sufrido una decadencia proporcional a la de la agricultura; la difícil cobranza de muchos censos, la pérdida de los que son contra la Real Hacienda y la destrucción de muchas casas y la enajenación de otras, son otras tantas causas de la baja de las rentas"20.

\footnotetext{
19 De suponer el subsidio menos del 3 por 100 del gasto, llegó a representar algún año cerca del 8,5.

20 AUS, Claustros, 262, fol. 95 r y vto. Sesión de 28-VI-1815.
} 
Resumiendo los argumentos principales, por una parte, la doble cara de la ofensiva fiscal de la Real Hacienda: diezmos de exentos, contribución directa, pero también impagos de sus deudas, es decir, doble presión fiscal, la del acreedor y la del deudor, mal pagador de empréstitos o vales. Por la otra, el fraude de los labradores. Por último, la desvalorización del patrimonio por las enajenaciones efectuadas y el menor valor de las rentas. Hay un aspecto del fraude que merece comentarse, el de los diezmos novales. El texto sugiere una lectura ricardiana; la gran oleada roturadora sobre tierras concejiles que se produjo durante y después de la guerra, rompiendo el "frente antirroturador" de señores y ganaderos trashumantes (Llopis, 2002, p. 129), tenía la virtud de aprovechar la fertilidad acumulada durante largo tiempo con la ventaja de una menor renta de la tierra respecto de las tierras antiguas, donde el descenso de la curva de producción hacía más gravoso el pago de la renta. La Universidad se queja de no participar en este nuevo "botín"; que al final fueran los párrocos quienes controlaran parte del excedente, como sugiere el autor del informe, iba a depender de un poder de convicción ciertamente a la baja, como lo muestra el pasar de las amenazas de las penas eternas a culpar a los "usurpadores de diezmos" de la mortalidad catastrófica de principios de $\operatorname{siglo}^{21}$. Aunque las relaciones entre economía y población no pueden ser mecánicas, no es improbable que la denominada "huelga de diezmos", más factible de llevarse a cabo sobre las tierras nuevas concejiles, junto con el proceso deflacionista, que hizo accesible el precio del pan, hubiesen facilitado el intenso crecimiento demográfico, que fue tanto un estímulo como una consecuencia de los procesos de ocupación de nuevas tierras y de aumento de la superficie agraria $^{22}$.

La llegada del Trienio, con la abolición del medio diezmo, añadió un escalón más al incumplimiento del pago de las tercias, resintiéndose el medio diezmo restante de esta medida; las juntas encargadas del reparto del mismo, aunque exageraran interesadamente la crisis de recaudación (Canales, 1985), reflejaban una situación real: en la contabilidad de la Universidad de los cursos 1821-1823, nada se apuntó en la cuenta de cada administración, y lo que entregó la junta de partícipes seculares de diezmos no llegó a 60.000 reales, menos del 5 por 100 de lo que se solía recaudar por tercias líquidas al acabar el siglo XVIII. Los ingresos atípicos que ayudaron a malvivir a profesores y dependientes vinieron de la enajenación de vales reales (pero con desfalcos del 80 por 100 o más), de las últimas rentas de América y de los derechos de

21 “Creo que no erraré (decía el obispo de Ciudad de Rodrigo en abril de 1804, cuando los hospitales se llenaban de enfermos y la ciudad de emigrantes huyendo del hambre) que una de las causas porque Dios nos castiga tan fuerte y visiblemente como lo estamos experimentando en el presente año, es la infidelidad, los fraudes, y los hurtos que se cometen en la paga de Diezmos". Archivo Diocesano de Ciudad Rodrigo, Pastoral, 26-IV-1804.

22 Véanse los comentarios de Pérez Moreda en Robledo, Castells y Romeo (eds.) (2003). Parafraseando a Labrousse, podríamos decir que "los pobres ganaron la vida"; Vilar (1964), p.94. 
matrícula, que empezaron a tener alguna importancia. Nada hay más negativo para la fortaleza de un tributo que sus frecuentes alteraciones. Finalizado el Trienio, la segunda restauración del absolutismo pareció que alentaba una recuperación del ingreso, siendo éste, de hecho, uno de los objetivos de aquélla, pero se trataba de un espejismo; si se querían cobrar los diezmos, había que apoyarse en la mera violencia que ejercían los voluntarios realistas, registrando las casas de los labradores para ver quién pagaba con exactitud (Madoz, 1835, p. 6). Al igual que la Inquisición no se pudo restaurar, tampoco el diezmo volvió a los niveles de antaño, de modo que los ingresos brutos acabaron estabilizándose en torno a 300.000-400.000 reales, lejos de los 2 millones de 1799-1800. No estaba ya en el Antiguo Régimen la salvación para la Universidad de Salamanca, como no lo estaba para la antigua nobleza y otros señores cuyas rentas también declinaban en esos años.

\subsection{De la vieja a la nueva hacienda: un sistema mixto de financiación, 1840-1900}

Sin posibilidad de recuperar los diezmos, la Universidad encaminó sus esfuerzos en la década de 1840 a lograr el pago de las indemnizaciones que, como otros partícipes laicos, tenía derecho a percibir, reconociéndosele una suma cercana a los 14 millones de reales (Cuadro 4). La base para la indemnización se fijó en la percepción decimal del período 1827-1836, lo cual ya suponía una merma importante del capital, al acumularse el escaso rigor en el diezmar y el bajo nivel de los precios de aquellos años; claro que mejor era eso que nada. Con un capital nominal en deuda pública de cuantía elevada pero falto de liquidez (el claustro se inclinó por no adquirir bienes nacionales) y con un número de alumnos en descenso, la financiación autónoma de la universidad estaba en entredicho. Al presentarse el "presupuesto" del curso 1840-1841, se evaluaron los ingresos en 83.038 reales. De esa cantidad, casi la mitad provenía del importe de matrículas y el resto lo constituían rentas y censos tradicionales, que no tardarían en desaparecer. Con tales ingresos, que suponían menos de la décima parte de lo ingresado por tercias (líquidas) al inicio del siglo, no se cubrían del todo los sueldos de los profesores de las facultades mayores (96.000 reales), sin contar los de los empleados (45.466 reales), que también había que pagar.

En tales circunstancias, y con la filosofía vigente de "hacer economías", se corría el riesgo de que se suprimiera algún centro. La proximidad de la Universidad de Valladolid, un centro en ascenso de rentas y alumnos (pasaban de mil los matriculados en 1840-45), amenazaba la supervivencia del estudio salmantino; en junio de 1842, el claustro tuvo que enfrentarse al peligro de que la Administración se viera obligada a decantarse por una $u$ otra universidad. Sin colegios mayores y sin conventos, que alimentaran las clientelas de la burocracia civil y eclesiástica, es comprensible que la universidad salmantina se redujera a la mínima expresión (dos o 
IMPORTE DE LOS BIENES VENDIDOS Y RECONOCIMIENTO DE DERECHOS DE LA UNIVERSIDAD DE SALAMANCA, 1855-1864

\begin{tabular}{lcc}
\hline & Reales de vellón & $\%$ \\
\hline Fincas de la Universidad & 5.125 .364 & 16,1 \\
Fincas de los Colegios & 5.205 .817 & 16,3 \\
Indemnización diezmos de la Universidad & 13.763 .500 & 43,1 \\
Indemnización diezmos de los Colegios & 7.826 .400 & 24,5 \\
\hline Total & $\mathbf{3 1 . 9 2 1 . 0 8 1}$ & $\mathbf{1 0 0 , 0}$ \\
\hline
\end{tabular}

Fuente: Elaboración según Memoria. Anuario de la Universidad de Salamanca, 1864-65.

tres centenares de matriculados), máxime teniendo en cuenta que, todavía en 1860, la ciudad de Salamanca no había recuperado la población de 1787.

El Cuadro 4 nos muestra la imagen final de la autonomía financiera de una institución centenaria. Al carecer de rentas propias, de suficiente alumnado y sin una implicación significativa del Estado en financiar la enseñanza superior, el estudio salmantino tenía pocos más activos que la historia para evitar su extinción. Durante más de medio siglo, se defendió con toda la retórica posible- - desde las Partidas a la Novísima Recopilación- para mantenerse como institución docente; y si lo consiguió fue menos por la apelación a la historia que porque acabó corrigiéndose el proceso de centralización financiera de los liberales, como demuestra el episodio de las facultades libres.

En efecto, tuvo que darse el cambio político de la Revolución de 1868 para que, mediante la libertad de enseñanza, pudiera rectificarse el declive de la universidad. En Salamanca, la Junta Revolucionaria se anticipó a los decretos de Ruiz Zorrilla y a disposiciones posteriores que pondrían en marcha la nueva regulación, posibilitando los estudios de medicina y de ciencias. A diferencia de otras instituciones, que se vieron obligadas a cerrar sus puertas en 1874 (por ejemplo, las universidades libres de Córdoba o Murcia), el compromiso del Ayuntamiento, como gestor, y de la Diputación, como patrocinadora económica, permitió que la Universidad de Salamanca mantuviera las facultades de Medicina y Ciencias hasta $1904^{23}$.

23 Este apartado se desarrolla más ampliamente en Robledo e Infante (2004). 
La Diputación se comprometió a aportar 37.500 pesetas anuales, cantidad que venía a suponer un 4-5 por 100 de sus ingresos totales. Junto a dicha subvención, la partida clave para financiar las facultades libres la constituyeron las tasas académicas, que de 1880 a 1902 aportaron un promedio del 60 por 100; hubo años, al final del siglo, en los que las tasas cubrieron por sí solas los gastos e, incluso, posibilitaron el superávit. Los servicios administrativos de la Universidad se encargaban de recoger los pagos de alumnos a cuenta de la "empresa" del Ayuntamiento, como ilustra el episodio de malversación que tuvo que afrontar el joven Rector Unamuno ${ }^{24}$ (posiblemente inducido por el superávit citado).

Tuvieron que ser las "corporaciones populares", especialmente la Diputación, las que hicieran posible en Salamanca y en otros lugares (Sevilla, Zaragoza, Oviedo) la continuidad de las enseñanzas científicas durante varios decenios. Un argumento más para valorar el papel de los otros presupuestos, los correspondientes a las haciendas locales o provinciales, de tanta importancia en la vida de los ciudadanos por ser las administraciones más cercanas y las que proporcionaban la mayoría de servicios sociales, si bien con bastantes limitaciones por la desatención que, "a sabiendas", practicó el Estado para dotarlas con recursos suficientes $^{25}$.

Una breve alusión a la evolución de la matrícula y del gasto nos permite ofrecer una perspectiva a más largo plazo (Cuadro 5) ${ }^{26}$. La matrícula, estabilizada en torno a 400 alumnos al inicio de la Restauración, se duplicó al permitirse la matrícula libre mediada la década de los ochenta, creciendo la autofinanciación y cubriendo las tasas el 90 por 100 del gasto, al acabar el siglo, en las facultades oficiales de Derecho y Filosofía y Letras; en la facultad de Derecho llegó a haber, por entonces, cuatro veces más alumnos libres que oficiales. Como no había una política presupuestaria de apoyo a la universidad, el gasto por alumno se redujo a la mitad. Al integrarse las facultades libres bajo la tutela del Estado a partir de 1904, aumentó el déficit que debía cubrir el presupuesto, pues se incorporaban facultades experimentales y profesores que tenían remuneraciones inferiores y debían equipararse a las del resto. En consecuencia, bajó la autofinanciación, pero el mismo proceso de fines de siglo -aumento de la matrícula y avances limitados del gasto público- hizo que, al final de la Dictadura, las tasas fueran capa-

24 En 1902 —explicaba Unamuno-, "se descubrió en esta Secretaria una filtración de fondos de las Facultades libres que iban a parar al bolsillo del oficial primero. Filtración que arranca de quince años ¡Cosa de doce mil duros!". El Ayuntamiento fue el principal perjudicado. Unamuno tuvo que adelantar cinco mil pesetas de los fondos universitarios y, luego, responder de ellos en una situación familiar apurada, Salcedo (1998), p. 135.

25 Fontana (2001), p. 14; Comín, 1996, p. 203.

26 Hasta 1905, gasto por alumno y porcentaje de tasas se refieren a facultades de Derecho y Filosofía y Letras; después, incluye también Medicina y Ciencias. 


\section{CUADRO 5}

NÚMERO DE ALUMNOS, GASTO POR ALUMNO Y PORCENTAJE DEL GASTO CUBIERTO POR TASAS EN LA UNIVERSIDAD DE SALAMANCA, 1882-1927

\begin{tabular}{lccc}
\hline & $\begin{array}{c}\text { Promedio } \\
\text { de alumnos }\end{array}$ & $\begin{array}{c}\text { Gasto por alumno } \\
\text { (pesetas de 1913) }\end{array}$ & $\begin{array}{c}\text { \% del gasto } \\
\text { cubierto por tasas }\end{array}$ \\
\hline $\mathbf{1 8 8 2 - 8 4}$ & 435 & 686 & 30 \\
$\mathbf{1 8 9 0 - 9 2}$ & 1.046 & 243 & 60 \\
$\mathbf{1 8 9 8 - 1 9 0 0}$ & 1.076 & 328 & 90 \\
$\mathbf{1 9 0 5 - 0 7}$ & 1.659 & 286 & 59 \\
$\mathbf{1 9 1 5 - 1 7}$ & 1.650 & 396 & 49 \\
$\mathbf{1 9 2 5 - 2 7}$ & 1.758 & 200 & 78 \\
\hline
\end{tabular}

Fuente: Elaboración según Memoria(s). Anuario(s) de la Universidad de Salamanca.

ces de financiar cerca del 80 por 100 del gasto, casi cuatro veces más que a finales del siglo XX, cuando el estado del bienestar se ha encargado de achatar la pirámide de financiación propuesta por el Duque de Rivas.

El Gráfico 3 recoge la tendencia del gasto total, que creció al 2,2 por 100 anual, y del gasto por alumno, descontada la inflación, a partir del momento en que las cuatro facultades fueron financiadas por el Estado. El gasto por alumno, fundamentalmente gasto corriente ${ }^{27}$, se movió en torno a las 300 pesetas, en cuantía similar al promedio español (Cuadro 9). La fluctuación a la baja, tanto del gasto total como del relativo, en el período 1913-1922, debe atribuirse a la inflación provocada por la coyuntura de la I Guerra Mundial y a un menor crecimiento del número de alumnos, sustento principal de la hacienda universitaria. La caída del gasto por alumno a 200 pesetas en los últimos años obedece al aumento de éstos, especialmente libres, que se aproximaron a 1.800 cuando en decenios anteriores se situaban en torno a 800-900. Como ilustra el Gráfico 3, el crecimiento del alumnado superó ampliamente al del gasto total (10 por 100 anual frente al 3 por 100 en 1920-1927).

27 Con un gasto en personal cercano al 90 por 100, muy poco podía reservarse para el gasto en material. Se trataba principalmente de material ordinario, pues la partida de material científico estuvo sin asignación específica durante varios años. 


\section{GRÁFICO 3}

ÍNDICES DEL GASTO TOTAL, POR ALUMNO (pesetas de 1913) Y NÚMERO DE ALUMNOS EN LA UNIVERSIDAD DE SALAMANCA (1903-1905=100)

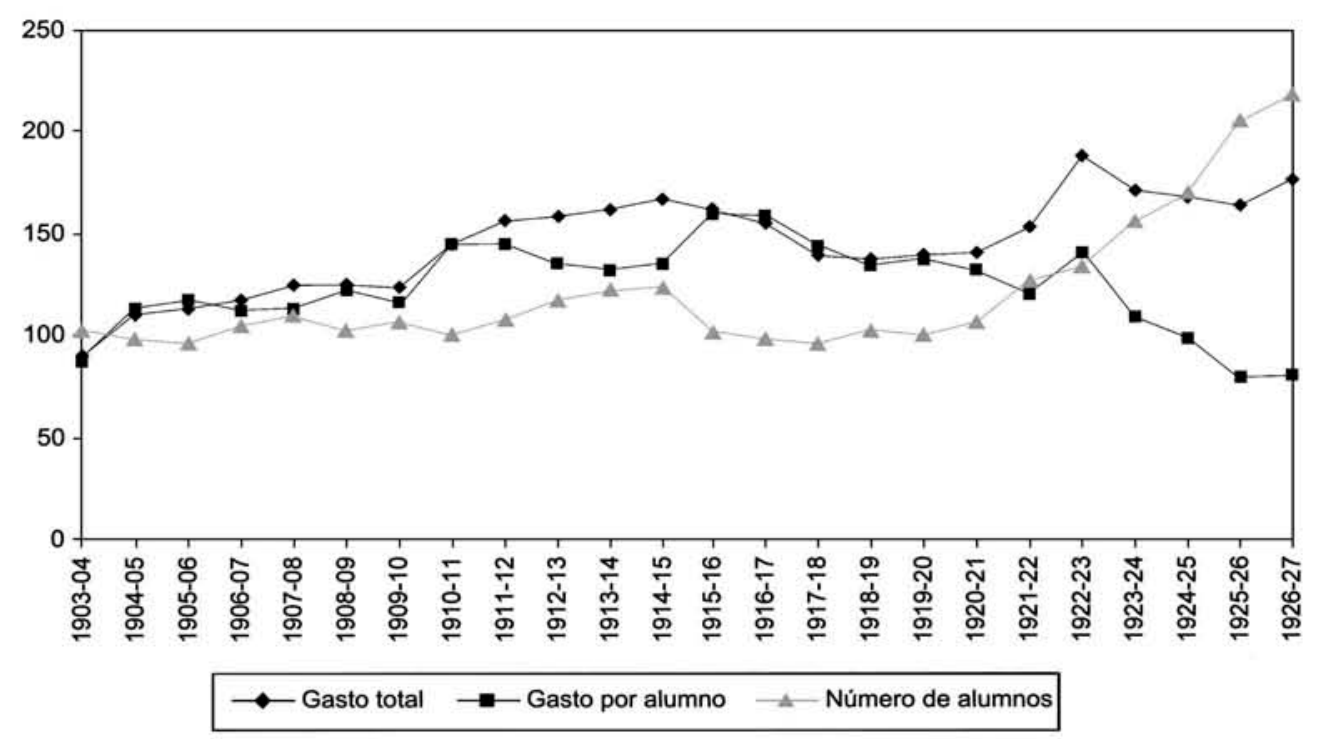

Fuente: Elaboración a partir de Memorias, Anuario(s) de la Universidad de Salamanca.

\section{Distribución del gasto educativo ¿Estaba la enseñanza superior sobredimensionada en España?}

Expuesto el marco general y el particular de la universidad salmantina, es el momento de plantearse el lugar ocupado por la financiación de la universidad dentro del sistema educativo español, un lugar cargado de prevenciones tanto en el pasado como en la actualidad. Conforme los censos de población iban ofreciendo la radiografía de un país de analfabetos -todavía en 1900, más del 50 por 100- , es comprensible que surgieran voces reclamando que debía ser la enseñanza primaria, y no la superior, la "más influida por el Estado", al igual que ocurría en Francia o en Inglaterra (Piernas Hurtado, 1885, p. 204). La literatura regeneracionista extendió el tópico de salvar al país corrigiendo el excesivo número de universidades. La "restauración de la raza" -como quería Macías Picavea (1899), p. 255- se lograría, entre otras reformas educativas, reduciendo a cuatro las diez universidades existentes, si bien tendrían que disponer de todas las facultades.

En historia económica, el análisis pionero lo efectuó hace algunos años C. E. Núñez (1992, pp. 288-327), cuando se refirió a "una mala política de distribución del 
gasto", pues en términos relativos se gastaba en las enseñanzas superiores "más de lo que era necesario y menos de lo que hubiera sido deseable en la instrucción primaria", hipótesis que ha sido recogida en un manual de Historia Económica de España y por otros autores ${ }^{28}$. El argumento principal para criticar este supuesto sobredimensionamiento del sistema universitario español era, podríamos decir, su elevado coste de oportunidad: la desviación del presupuesto educativo hacia los niveles superiores iba en detrimento de las tasas sociales de rendimiento, mucho más elevadas en la instrucción primaria (Núñez, 1992, p. 301). Y tal argumento se sostenía en dos tipos de información, la presupuestaria y la demográfica, cuya consistencia se discute a continuación.

Valoremos en primer lugar la idea del exceso de gasto público en pro de la universidad desde el punto de vista presupuestario, algo que en mi opinión tiene dos puntos endebles. El primero de ellos es que no se considera el hecho de que los ingresos por matrícula y grados servían para financiar buena parte del gasto de la enseñanza superior, tal y como advertían los contemporáneos ${ }^{29}$. En páginas anteriores, de forma general o respecto al caso de la universidad salmantina, se ha aludido a este asunto de la autofinanciación, que cabría matizar y cuantificar en la medida de lo posible.

El trípode rentas-tasas-créditos presupuestarios, configurado en el Trienio para financiar la universidad, había derivado después de 1855 en un esquema dual donde las tasas eran hegemónicas. Dada la importancia de tales ingresos, las universidades de mayor tamaño se encargaban de financiar a las pequeñas. Si nos remitimos al curso académico 1878-79, las universidades de Madrid y Barcelona tuvieron superávit, mientras que las pequeñas, Oviedo y Salamanca, sólo pudieron financiar el 53 por 100 del gasto de personal y el 33 por 100 del de material. Al final, del total de 2.602.413 pesetas que importó en aquel curso el gasto universitario en toda España, más del 95 por 100 fue financiado por los ingresos académicos ${ }^{30}$. El déficit de 116.145 pesetas es lo que propiamente deberíamos considerar como gasto neto por parte del Estado. El análisis de las variaciones en el importe de las tasas y en el número de alumnos podría explicar las oscilaciones de años posteriores.

28 Tortella (1995), p. 41; Terrón (2000), pp. 282-283 y 295.

29 Las pesetas invertidas en la enseñanza universitaria "casi se compensan (...) con los ingresos a que dan lugar las matrículas y expediciones de títulos". Piernas Hurtado (1885), p. 204. Macías Picavea (1899), p. 115, extiende el testimonio a la enseñanza secundaria, igual que Groizard (1899), p. 26, quien, teniendo en cuenta el importe de tasas, subvenciones de diputaciones e intereses de los valores correspondientes a los bienes de establecimientos de Segunda Enseñanza, estimaba que el Estado se beneficiaba en más de 700.000 pesetas.

30 Dirección General (1888), p. 279. Hace tiempo, se llamó la atención sobre el hecho de que la enseñanza superior hubiese sido costeada principalmente por los estudiantes, Peset (1974), pp. 745-751 y (1979). Por otra parte, una institución como la Escuela de Ingenieros de Barcelona pudo funcionar gracias a que los ingresos propios, más las subvenciones de Ayuntamiento y Diputación, financiaban el 70-80 por 100 del gasto, Riera (1993), p. 154. 


\section{CUADRO 6}

PORCENTAJE DE LA ENSEÑANZA FINANCIADA CON TASAS ACADÉMICAS EN ESPAÑA, 1878-1910

\begin{tabular}{lcccc}
\hline & $\begin{array}{c}\text { Enseñanza } \\
\text { Secundaria }\end{array}$ & $\begin{array}{c}\text { Escuelas } \\
\text { Universitarias }\end{array}$ & Facultades & Media ponderada \\
\hline $\mathbf{1 8 7 8 - 7 9}$ & 44 & n. d. & 96 & 79 \\
$\mathbf{1 8 8 9 - 9 0}$ & 52 & 29 & 63 & 52 \\
$\mathbf{1 9 0 0 - 0 1}$ & 84 & 31 & 94 & 82 \\
$\mathbf{1 9 0 9 - 1 0}$ & 66 & 38 & 76 & 64 \\
\hline
\end{tabular}

Fuente: Elaboración según Dirección General (1888) y Anuario(s) Estadístico(s) de la Instrucción Pública.

En buena lógica, por tanto, deberíamos descontar de la cantidad que figura en los presupuestos del Estado lo que los alumnos pagaban en metálico o en papel sellado; el mismo Ministerio se encargó a veces de precisar este aspecto con detalle ${ }^{31}$, recordándonos que, en las cuentas de la Intervención General del Estado y en las recopilaciones del Instituto de Estudios Fiscales (IEF), tanto los ingresos como los gastos se recogen siempre en términos brutos ${ }^{32}$.

El segundo punto endeble en la afirmación del sobregasto en la enseñanza universitaria se corrige con la presentación del Cuadro 7. En el Panel A, se presentan los datos del IEF, que son los que se suelen utilizar al referirse al gasto en educación (Núñez, 1992, pp. 304-307), y en el Panel B, éstos más los presupuestos municipales y provinciales dedicados a instrucción pública.

Se ha supuesto que los presupuestos municipales financiaban la enseñanza primaria y los de las diputaciones la enseñanza media, lo que no es totalmente exacto, pues había municipios (urbanos, sobre todo) que se hacían cargo de la enseñanza media y diputaciones que financiaban ciertos gastos de instrucción primaria e, incluso, en algunas provincias (como Salamanca y otras) una parte de la enseñanza superior,

31 En el curso 1909-10, lo recaudado en papel y metálico ascendió a 7.079.587,36 pesetas, mientras que el total de lo pagado sumaba 11.713.169,88 pesetas, resultando una diferencia de 4.633.582,52. En el Anuario Estadístico de la Instrucción Pública se insertó la siguiente anotación: "Esta es la diferencia entre lo pagado por el Estado y lo pagado en papel y metálico por los alumnos, pero como lo pagado en metálico, que asciende a 1.525.082,73 pesetas, no ingresa en el Tesoro, resulta que lo que al Estado ha costado la enseñanza universitaria, la de Institutos, Normales y Escuelas especiales en el curso de 1909 a 1910 asciende a 6.158.565,25 pesetas [sic, serían 6.158.665,25]". Anuario (1910), p. 537; una vez descontados los pagos, las universidades le costaron al Estado en aquel curso menos de 1 millón de pesetas corrientes...

Es decir, hay que restar a los gastos brutos de la enseñanza de la contabilidad oficial, los ingresos derivados de ese servicio, igual que para calcular los ingresos netos de los estancos del tabaco y de la sal, hay que sustraer los gastos realizados en esos establecimientos. 
CUADRO 7

GASTO EN EDUCACIÓN EN ESPAÑA, 1854-1879

(Miles de pesetas corrientes y porcentajes del total)

\begin{tabular}{lrlllllllll}
\hline \multicolumn{10}{c}{ Panel A. Presupuestos del Estado } \\
\hline & $\mathbf{1})$ & $\%$ & $\mathbf{( 2 )}$ & $\%$ & $\mathbf{( 3 )}$ & $\%$ & $\mathbf{( 4 )}$ & $\%$ & $\mathbf{( 5 ) = ( 3 + 4 )}$ & Total \\
\hline $\mathbf{1 8 5 4}$ & 48 & 1 & 398 & 11 & 2.450 & 68 & 700 & 20 & 88 & 3.596 \\
$\mathbf{1 8 5 5}$ & 28 & 1 & 405 & 11 & 2.324 & 65 & 800 & 23 & 88 & 3.557 \\
$\mathbf{1 8 5 6}$ & 106 & 3 & 392 & 11 & 2.270 & 63 & 845 & 23 & 86 & 3.613 \\
$\mathbf{1 8 5 7}$ & 218 & 5 & 427 & 11 & 2.369 & 59 & 1.005 & 25 & 84 & 4.019 \\
$\mathbf{1 8 5 8}$ & 248 & 6 & 349 & 8 & 2.778 & 66 & 858 & 20 & 86 & 4.233 \\
$\mathbf{1 8 5 9}$ & 249 & 6 & 384 & 9 & 2.966 & 70 & 658 & 15 & 85 & 4.257 \\
$\mathbf{1 8 6 0}$ & 270 & 6 & 370 & 9 & 2.959 & 68 & 748 & 17 & 85 & 4.347 \\
$\mathbf{1 8 6 1}$ & 278 & 6 & 605 & 14 & 2.875 & 64 & 711 & 16 & 80 & 4.469 \\
$\mathbf{1 8 6 2 - 6 3}$ & 409 & 6 & 942 & 13 & 4.439 & 63 & 1.249 & 18 & 81 & 7.039 \\
$\mathbf{1 8 6 3 - 6 4}$ & 264 & 5 & 648 & 14 & 2.755 & 58 & 1.094 & 23 & 81 & 4.761 \\
$\mathbf{1 8 6 4 - 6 5}$ & 258 & 6 & 636 & 13 & 2.741 & 58 & 1.084 & 23 & 81 & 4.719 \\
$\mathbf{1 8 6 5 - 6 6}$ & 130 & 3 & 610 & 13 & 2.961 & 66 & 792 & 18 & 83 & 4.493 \\
$\mathbf{1 8 6 6 - 6 7}$ & 9 & 0 & 564 & 14 & 2.781 & 68 & 720 & 18 & 86 & 4.074 \\
$\mathbf{1 8 6 7 - 6 8}$ & 134 & 4 & 231 & 6 & 2.997 & 77 & 522 & 13 & 91 & 3.884 \\
$\mathbf{1 8 7 8 - 7 9}$ & 176 & 4 & 404 & 9 & 3.316 & 73 & 639 & 14 & 87 & 4.535 \\
\hline
\end{tabular}

Panel B. Presupuestos del Estado, Diputaciones y Ayuntamientos

\begin{tabular}{|c|c|c|c|c|c|c|c|c|c|c|}
\hline & (1) & $\%$ & (2) & $\%$ & (3) & $\%$ & (4) & $\%$ & $(5)=(3+4)$ & Total \\
\hline 1854 & 6.800 & 57 & 1.964 & 16 & 2.450 & 21 & 700 & 6 & 27 & 11.914 \\
\hline 1855 & 6.824 & 57 & 1.955 & 16 & 2.324 & 20 & 800 & 7 & 26 & 11.903 \\
\hline 1856 & 7.043 & 58 & 2.000 & 16 & 2.270 & 19 & 845 & 7 & 26 & 12.158 \\
\hline 1857 & 8.120 & 60 & 2.045 & 15 & 2.369 & 17 & 1.005 & 7 & 24 & 13.539 \\
\hline 1858 & 11.079 & 63 & 2.756 & 16 & 2.778 & 16 & 858 & 5 & 21 & 17.471 \\
\hline 1859 & 11.604 & 64 & 2.957 & 16 & 2.966 & 16 & 658 & 4 & 20 & 18.184 \\
\hline 1860 & 15.361 & 67 & 3.907 & 17 & 2.959 & 13 & 748 & 3 & 16 & 22.974 \\
\hline 1861 & 15.984 & 67 & 4.447 & 18 & 2.875 & 12 & 711 & 3 & 15 & 24.017 \\
\hline $1862-63$ & 24.551 & 67 & 6.612 & 18 & 4.439 & 12 & 1.249 & 3 & 15 & 36.851 \\
\hline $1863-64$ & 17.605 & 68 & 4.509 & 17 & 2.755 & 11 & 1.094 & 4 & 15 & 25.963 \\
\hline 1864-65 & 17.962 & 68 & 4.524 & 17 & 2.741 & 11 & 1.084 & 4 & 14 & 26.311 \\
\hline $1865-66$ & 18.313 & 69 & 4.489 & 17 & 2.961 & 11 & 792 & 3 & 14 & 26.555 \\
\hline $1878-79\left(^{*}\right)$ & 22.801 & 72 & 5.000 & 16 & 3.316 & 10 & 639 & 2 & 12 & 31.756 \\
\hline
\end{tabular}

\footnotetext{
(1)=Enseñanza Primaria

(2)=Enseñanza Secundaria

(3)=Enseñanza Universitaria

(4)=Profesional, técnica y especial
}

$\left(^{*}\right)$ El dato de Enseñanza Secundaria de 1878-79 del Panel B es estimado.

Fuente: Elaboración a partir de Anuario(s) Estadístico(s) de España (1857-68), Dirección General (1888), y Datos básicos. 
pero resulta imposible deslindar bien estas excepciones. Por otra parte, desconocemos qué porción de los "gastos imprevistos" o "extraordinarios" que suelen figurar en los presupuestos municipales y provinciales, ascendiendo a cantidades significativas, debe imputarse a instrucción pública. Esto hace que los datos de enseñanza primaria y media del Cuadro 7, Panel B, deban considerarse subestimados; puede ocurrir, también, que alguno de los Datos Básicos sea incorrecto ${ }^{33}$.

A la vista del Cuadro 7, la distribución del gasto en educación cambia notablemente y se corrige el desequilibrio que solía comprobarse a favor de la enseñanza superior antes de 1880. Si se tiene en cuenta sólo el presupuesto del Estado, la enseñanza universitaria (más la profesional, técnica y especial) alcanza porcentajes por encima del 80 por 100 del total, pero si se incluyen también los provinciales y municipales, es decir, el conjunto de las administraciones públicas, ese porcentaje baja al 15-25 por 100, aproximadamente.

El segundo argumento para sostener el sobredimensionamiento del gasto universitario español es de carácter demográfico, y parece tener más consistencia, en principio, que el de índole hacendística. En efecto, ya los contemporáneos criticaron el excesivo número de alumnos en algunos niveles o carreras, respecto a otros paí$\operatorname{ses}^{34}$, y la comparación que hace C. E. Núñez, con los datos de la estadística internacional recogidos por P. Flora, muestra una desproporción llamativa por el gran retraso de la educación primaria, lo que hace aparecer al resto de enseñanzas más "adelantadas", (aunque los niveles de secundaria, o superior, no fueran muy altos ${ }^{35}$ ). El análisis de Núñez, desde luego, ha demostrado un escaso compromiso con la escuela pública en España ${ }^{36}$.

No obstante, me atrevo a hacer tres observaciones. La primera de ellas es de orden metodológico. Como advierte Mitchell, de todas las materias objeto de la estadística, ninguna ofrece menos uniformidad en el tiempo y en el espacio ("not even crime") que las referidas a educación (Mitchell, 2003, p. 869). Convendría tener la seguridad de que el punto de comparación es homogéneo pues, en el caso de España, las cifras recogidas por los Anuarios Estadísticos engloban la enseñanza oficial y

33 Como el llamativo dato de 1866-67 (9.000 pesetas en Enseñanza Primaria), Datos Básicos (1976), vol. I, p. 833. He consultado los Presupuestos de ese año y del siguiente y no hay ninguna diferencia significativa en las partidas que deben haber servido para precisar ese dato, sin duda erróneo.

34 La comparación entre los alumnos de secundaria de Madrid (el 11 por 1.000 de sus habitantes) y de París (el 6 por 1.000) se cita para aconsejar la subida de la matrícula en Boletín Oficial del Ministerio de Comercio (1848), 25, pp. 517-518. El elevado número de alumnos de Derecho se menciona después.

35 Si en Zamagni (1993), pp. 188-191, en vez de comparar la educación secundaria con la primaria, se compara aquélla con la población de 15-19 años, se comprueba que, hacia 1910, España tenía la mitad o menos de estudiantes de secundaria que Bélgica, Italia, Suecia y Gran Bretaña, y casi ocho veces menos que Alemania.

36 Un repaso a las diversas teorías sobre capital humano y desarrollo puede verse en Núñez y Tortella, eds., (1993), pp. 15-38. 
libre; ésta última, que podía suponer un 40-50 por 100 del total (Cuadro 9), era por definición más fuente de renta que consumidora de servicios universitarios, de personal o de material científico.

Aun aceptando cierto grado de homogeneidad en la estadística de alumnos, convendría saber si también la había en los planes de estudio. Un ejemplo claro es la disparidad en la carrera de Derecho que, desde 1845, duraba en España seis o siete años frente a los tres años Francia ${ }^{37}$. Una mayor permanencia, en este caso el doble de años para un sector importante del alumnado, inflaba el número de estudiantes matriculados, lo que debería tenerse en cuenta al hacer comparaciones internacionales.

La alusión a la carrera de Derecho da pie a una segunda observación, relativa a la composición del alumnado. La Reseña Estadística de 1888 llamó la atención sobre el exceso de alumnos de Derecho, casi tres veces más que los de Alemania o Francia, asunto sobre el que volvió el Ministro de Instrucción Pública años después ${ }^{38}$. La intención de los liberales de reducir el excesivo número de abogados subiendo la matrícula había provocado el efecto contrario, al ser Derecho la única facultad mayor con la que contaban todas las universidades. Es decir, quizá el problema no resida tanto en que "la pirámide educacional fuera de base relativamente estrecha y cúspide ancha", según afirma Núñez, como en la estructura de esa cúspide, con carreras hipertrofiadas como Derecho - hasta 1900, fue frecuente que ésta albergase a cerca del 40 por 100 de los matriculados ${ }^{39}$ (Cuadro 9)—, contándose, en consecuencia, con escasísimos recursos para las disciplinas experimentales, salvo que el cliente pagara el servicio.

Como se expuso en 1917, las dotaciones para enseñanzas experimentales no provenían del aumento de las partidas presupuestarias, sino del de las matrículas o derechos de prácticas que pagaban los alumnos; así ocurrió en 1877, gestionando los claustros estos ingresos para la adquisición de instrumental, pero sólo durante cuatro años: el Estado se incautó de ellos para atender otros gastos corrientes (!). Los ejercicios prácticos de laboratorio se costeaban con aumentos de la matrícula de quienes cursaban estas materias a partir de $1900^{40}$.

37 El dato de Francia en Museo Pedagógico (1919a). La duración de la carrera de Derecho en España, en Blasco Gil (2000), pp. 107-110 y 143-146. Es cierto que, como hoy, era posible acortar esa duración, pero un análisis del rendimiento académico en la Facultad de Derecho de Valencia, arroja una duración efectiva con un valor modal de 5-6 años, Blasco Gil (2000), p. 173.

38 Dirección General (1888), p. 316, Ministerio (1910), Boletín (1841), Álvarez Morales (1974), p. 384.

39 En otros países, Derecho también predominaba, pero no tanto; en 1890, el promedio estaba en el 27,4 por 100, Flora (1983), pp. 535-632.

40 Izquierdo (1917), pp. 48-49. Este testimonio he podido conocerlo gracias a Sánchez Ron (1999), p. 101. Ver, también, Carracido (1917), p. 389; Murua (1915), p. 16. Esto no debe ocultar los avances de la investigación española durante el primer tercio de siglo, Peset y Hernández Sandoica (1994). 
Finalmente, cabe una tercera observación a la comparación internacional basada en las tasas brutas de escolarización. Aun aceptando que se utilizan indicadores homogéneos -en los que España se aparta poco de la tendencia general, especialmente en el siglo $X^{41}$ - lo decisivo está en comparar el gasto por alumno para medir el compromiso de cada país con la universidad, estimación que no es fácil hallar desagregada en las estadísticas internacionales. A tenor de lo que ocurre en la actualidad - cuando el gasto medio por universitario en España apenas alcanza el 65 por 100 del correspondiente a los países de la $\mathrm{OCDE}^{42}$-, no parece una extrapolación arriesgada suponer que ese diferencial era mayor en el pasado, teniendo en cuenta el gasto en instrucción pública del siglo XIX y principios del $X X^{43}$. Algunos datos aislados confirman la consistencia de esta hipótesis. Hacia 1933, el gasto en educación superior por alumno era en España de 71 dólares; Finlandia y Francia lo superaban en un 61 por 100 y en un 84 por 100, respectivamente (114 y 129 dólares), Inglaterra y Gales lo triplicaban (217 dólares) y Suecia lo quintuplicaba ampliamente (362 dólares ${ }^{44}$ ). Las publicaciones del Museo Pedagógico Nacional, que recogieron información sobre las universidades de varios países, dieron cuenta del superior compromiso de éstos con la enseñanza universitaria en diversos campos $^{45}$. Parte de esta información aparece en el Cuadro 8, donde - con las precauciones antes expuestas respecto a las cifras de alumnos- puede advertirse que, en el primer tercio del siglo $\mathrm{XX}$, el esfuerzo presupuestario español fue insuficiente y el diferencial del gasto por universitario continuó siendo significativo, aunque la distancia se redujo (del 38 por 100 del correspondiente al alumno francés en 1899, llegó al 55 por 100 en 1933).

En 1910 y 1930, España, con 0,9 y 1,5 por 100 de universitarios respecto a la población de 20-24 años, estaría por debajo de la media (1,1 y 1,7 por 100) de los 13 países que incluye Flora (1983), pp. 535-632.

Consejo Económico y Social (2002), p. 511. Esto sucede cuando la renta por habitante sobrepasa ya el 83 por 100 de la media europea.

43 A principios del siglo XX, el gasto por habitante en instrucción pública era en España unas tres veces menor que en Francia, Alemania y Reino Unido, pero la brecha se ensanchaba hasta siete veces o más antes de 1887; hasta 1901, también fue inferior al de Italia, Tedde (1985), p. 254.

Datos deducidos de Annuaire (1934); para la cotización del dólar según las distintas divisas, Officer (2002).

El grado de autofinanciamiento tuvo que ser mayor en España. En Francia, el presupuesto de cada universidad comprendía, aparte de ingresos por tasas y subvenciones del Estado, donaciones, rentas de fondos depositados, y subvenciones de departamentos, municipios y otras asociaciones, Museo Pedagógico (1919a), p. 65. En Inglaterra, las dos universidades más famosas, Oxford y Cambridge, carecían de subvenciones del Estado, siendo decisivas en su caso, más que las tasas, las contribuciones de los Colegios, que, en 1907, tenían unas rentas de casi 13 millones de pesetas, es decir, lo mismo que el conjunto de lo presupuestado en España para universidad, enseñanza media, enseñanza especial y enseñanza técnica, Museo Pedagógico (1919c), pp. 20-21, y Datos básicos (1976), vol. I., p. 917. 


\section{CUADRO 8}

COMPARACIÓN DEL ALUMNADO UNIVERSITARIO ESPAÑOL Y FRANCÉS,

Y DEL GASTO POR ESTUDIANTE (dólares corrientes)

\begin{tabular}{lrrrr}
\hline & $\begin{array}{c}\text { España } \\
(\mathbf{1 8 9 9 )}\end{array}$ & $\begin{array}{c}\text { Francia } \\
\mathbf{( 1 8 9 7 )}\end{array}$ & $\begin{array}{c}\text { España } \\
(\mathbf{1 9 3 3 )}\end{array}$ & $\begin{array}{c}\text { Francia } \\
\text { (1933) }\end{array}$ \\
\hline (1) Estudiantes universitarios (miles) & 18,8 & 28,5 & 31,3 & 85,9 \\
(2) \%॰ sobre población de 20-24 años & 12,1 & 8,5 & 14,6 & 25,4 \\
(3) Gasto universitario (miles de dólares) & 690,5 & $2.761,0$ & $2.464,0$ & $10.899,0$ \\
(4) Índices de (3) (España=100) & 100,0 & 400,0 & 100,0 & 442,0 \\
(5) Dólares por universitario & 37,0 & 97,0 & 71,0 & 129,0 \\
(6) Índices de (5) (Francia=100) & 38,0 & 100,0 & 55,0 & 100,0 \\
\hline
\end{tabular}

Fuente: Para el número de estudiantes, promedio de 1932 y 1933, Mitchell (2003). Para el gasto de 1899 de España, Datos básicos (1976); el de Francia, en Museo Pedagógico (1919a), p. 16; los de 1933 de ambos países, en Annuaire (1934). Para la cotización del dólar, Officer (2002), salvo los datos de fines del XIX, donde el tipo de cambio aplicado es de los años previos a la I Guerra Mundial, lo que sin duda favorece a los datos españoles de 1899.

En suma, en gasto por estudiante universitario, España estaba mucho más lejos de otros países europeos de lo que indicaban sus tasas de escolarización superior, perdiendo fuerza el argumento del "fuerte apoyo a los estudios universitarios", que se aviene mal, además, con otros indicadores, como el de la investigación científica o el de la remuneración del profesorado. Los Cuadros 8 y 9 evidencian la insuficiencia del aumento del gasto universitario, que en términos constantes creció al 0,64 por 100 anual entre 1857 y 1900, frente al 1,4 por 100 del PIB. Ello, añadido al fuerte incremento del número de alumnos, deprimió los niveles del gasto por universitario casi un 50 por 100, mientras el PIB per cápita aumentaba un 63 por 100. En las tres primeras décadas del siglo XX, el gasto en educación universitaria creció al 5,4 por 100 anual (mientras el PIB lo hacía al 2,3 por 100), pero no olvidemos que estaba financiado en gran parte por el alumno; se corregía la tendencia descendente del gasto por universitario, aunque situándose siempre por debajo de la tasa de crecimiento del PIB per cápita. El Gráfico 4 ilustra sobre todo ello. 


\section{GRÁFICO 4}

ÍNDICES DEL PIB REAL PER CÁPITA Y GASTO POR UNIVERSITARIO, 1850-1929

(pesetas de 1913, 1857-61=100)

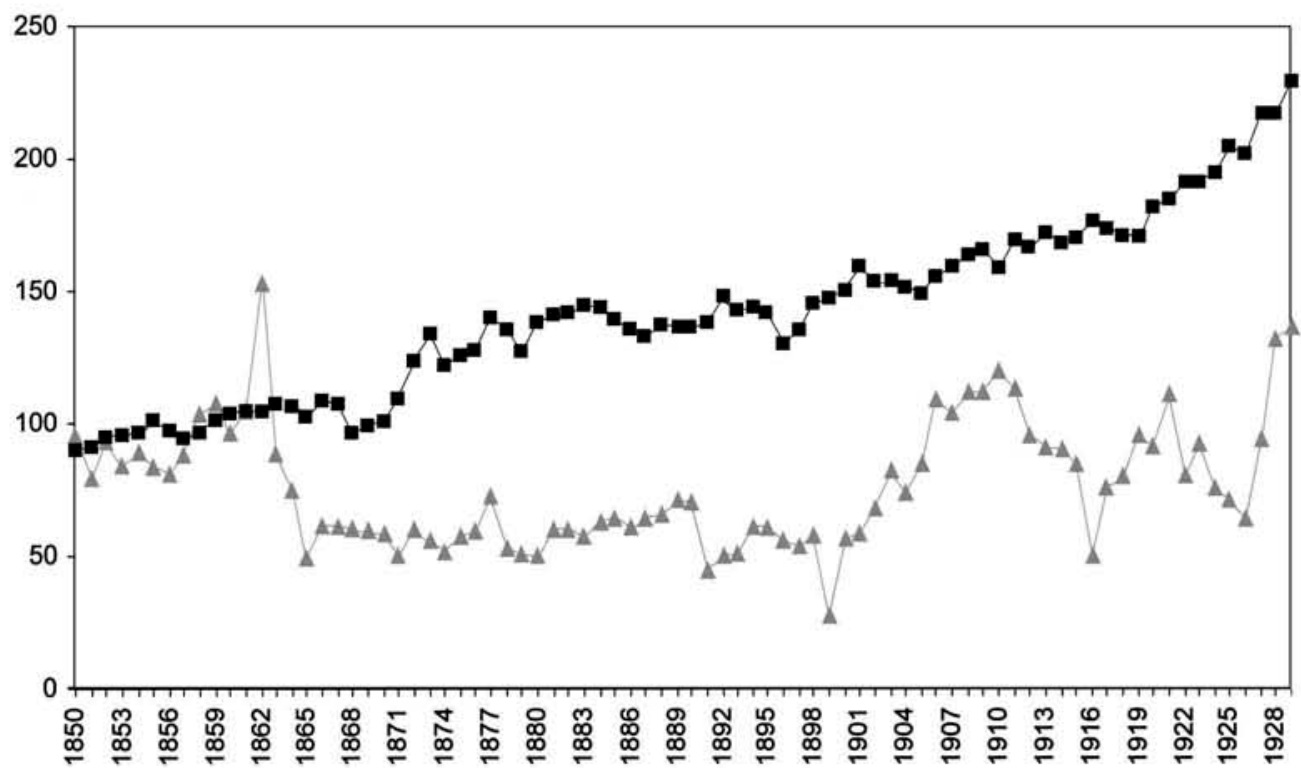

$\rightarrow$ - PIB p.c. $\quad$ - Gasto

Fuente: Elaboración a partir de Prados (2004) y datos del Cuadro $9^{46}$.

Si se me permite una reflexión historiográfica, considero que, una vez más, pierde relevancia apelar al comodín del atraso agrario como la explicación del lento crecimiento español, si se acepta que el principal diferencial con los países del entorno estaba en el atraso educativo, no sólo por la conocida persistencia del analfabetismo, sino también por los bajos niveles de inversión en enseñanza superior (especialmente en facultades experimentales). Los cambios institucionales que introdujo en el sector agrario la reforma liberal, no faltaron en la universidad: la centralización financiera y académica, y la secularización se impusieron siguiendo el modelo francés. No residía ahí el problema; estaba más bien en que España había imitado a Francia en el modelo de centralización liberal, pero no la había seguido en el gasto por alumno. 


\section{CUADRO 9}

NÚMERO DE ALUMNOS UNIVERSITARIOS Y GASTO, 1785-1933.

(pesetas corrientes y constantes, 1913, e índices, 1857-61=100)

\begin{tabular}{lrrrrrrrrrrr}
\hline $\mathbf{A N ̃ O S}$ & $\mathbf{( 1 )}$ & $\mathbf{( 2 )}$ & $\mathbf{( 3 )}$ & $\mathbf{( 4 )}$ & $\mathbf{( 5 )}$ & $\mathbf{( 6 )}$ & $\mathbf{( 7 )}$ & $\mathbf{( 8 )}$ & $\mathbf{( 9 )}$ & $\mathbf{( 1 0 )}$ & $\mathbf{( 1 1 )}$ \\
\hline $\mathbf{1 7 8 5}$ & 10.692 & 134,9 & 13,9 & n.d. & n.d. & n.d. & n.d. & n.d. & n.d. & 28,2 & n.d. \\
$\mathbf{1 7 9 7}$ & 12.538 & 158,2 & 16,7 & n.d. & n.d. & n.d. & n.d. & n.d. & n.d. & n.d. & n.d. \\
$\mathbf{1 8 3 1}$ & 9.864 & 124,4 & 9,8 & n.d. & n.d. & n.d. & n.d. & n.d. & n.d. & 41,3 & n.d. \\
$\mathbf{1 8 4 7 - 4 8}$ & 8.291 & 104,6 & 6,5 & 2.192 & 78,6 & 2.631 & 88,0 & 317,4 & 84,2 & 48,8 & n.d. \\
$\mathbf{1 8 5 7 - 6 1}$ & 7.927 & 100,0 & 6,2 & 2.789 & 100,0 & 2.989 & 100,0 & 377,1 & 100,0 & 52,6 & n.d. \\
$\mathbf{1 8 6 2 - 6 8}$ & 11.145 & 140,6 & 8,7 & 3.112 & 111,6 & 3.128 & 104,7 & 280,7 & 74,4 & 35,0 & n.d. \\
$\mathbf{1 8 7 8 - 7 9}$ & 16.874 & 212,9 & 12,4 & 3.316 & 118,9 & 3.291 & 110,1 & 195,0 & 51,7 & 38,0 & n.d. \\
$\mathbf{1 8 8 8 - 9 2}$ & 18.950 & 239,1 & 12,5 & 3.756 & 134,7 & 4.060 & 135,8 & 214,2 & 56,8 & 58,0 & 51,0 \\
$\mathbf{1 8 9 9 - 1 9 0 0}$ & 18.807 & 237,3 & 12,1 & 3.639 & 130,5 & 3.860 & 129,1 & 205,2 & 54,4 & 38,5 & 54,8 \\
$\mathbf{1 9 0 6 - 1 0}$ & 15.203 & 191,8 & 9,5 & 5.503 & 197,3 & 6.432 & 215,2 & 423,1 & 112,2 & 29,8 & 41,4 \\
$\mathbf{1 9 1 4 - 1 8}$ & 24.379 & 307,5 & 14,1 & 7.598 & 272,4 & 6.740 & 225,5 & 276,5 & 73,3 & & 51,0 \\
$\mathbf{1 9 1 9 - 2 3}$ & 24.696 & 311,5 & 15,1 & 14.722 & 527,9 & 8.958 & 299,7 & 362,7 & 96,2 & & 48,7 \\
$\mathbf{1 9 2 4 - 2 8}$ & 37.524 & 473,4 & 18,8 & 21.151 & 758,4 & 12.352 & 413,2 & 329,2 & 87,3 & & 56,0 \\
$\mathbf{1 9 2 9 - 3 3}$ & 33.104 & 417,6 & 15,4 & & & & & & & & \\
\hline
\end{tabular}

(1) Número de alumnos, promedio anual.

(2) Índice de (1).

(3) Alumnos en \% sobre población de 20-24 años.

(4) Gasto universitario, promedio anual en miles de pesetas corrientes.

(5) Índice de (4).

(6) Gasto universitario, promedio anual en miles de pesetas de 1913.
(7) Índice de (6).

(8) Pesetas constantes por alumno.

(9) Índice de (8)

(10) Porcentaje de alumnos matriculados en Derecho.

(11) Porcentaje de alumnos matriculados como libres.

Fuentes: Elaboración a partir de Guía Histórica [1786], citada en La Fuente (1889), IV, p. 153; Censo de Godoy; Gaceta de Madrid, № 24, 23-II-1833, Boletín Oficial del Ministerio de Comercio, Instrucción Pública (1848), Anuario(s) Estadístico(s) (1857-1868, 1914-1933), Dirección General (1888), Anuario de Instrucción Pública (18891892) Anuario(s) Estadístico(s) de la Instrucción Pública (1901, 1912), Datos Básicos ${ }^{47}$.

47 De 1785 a 1861, la tasa se refiere al grupo de 21-25 años; en los años 1787 y 1797, cuyos censos sólo informan del grupo 16-25 años, se ha estimado tal grupo aplicando la distribución de edades del promedio de los censos de 1857 y 1860; para los demás casos, se ha referido la población universitaria al censo de población inmediato o al promedio intercensal; para los datos demográficos, Nicolau (1989); el gasto toma en consideración los mismo años que los de población universitaria, salvo en 1899, que el gasto es el de 1900, y en 1906-10, que el alumnado es promedio de 1906-07 y 1909-10. El dato de 1847-48 se ha calculado descontando la cifra de seminarios y añadiendo la matrícula de Filosofía de 1857-58, pues en 1847 estaba dentro de la segunda enseñanza, y el gasto es el promedio de 1845 y 1849. Los alumnos de Derecho en 1785, 1831, 1847-48 son la suma de los de Leyes y Cánones. Los datos de las columnas (10) y (11) correspondientes a 1888-92 se refieren a los cursos 1890-91 y $1892-93$. 


\section{Conclusiones}

El análisis de la financiación de la universidad española permite establecer varias conclusiones sobre el impacto de la crisis del Antiguo Régimen y la reforma universitaria liberal, el modelo de centralización impuesto por los liberales y la importancia del gasto público dedicado a la universidad, aspecto éste que deja muy malparada cualquier retórica sobre el Alma Mater.

1) La historia agraria ofrece un buen observatorio para analizar cómo el ingreso de la universidad dependía de la evolución de las cosechas y de la disputa por el reparto del diezmo entre los distintos perceptores, algo que se hizo más conflictivo al inicio del siglo XIX. La Iglesia, aquejada de los mismos males que el resto de instituciones rentistas, no estaba dispuesta a conceder participación en las rentas decimales; el equilibrio Señores (donde cabe incluir a la universidad)-IglesiaHacienda, que sustentaba el consenso fiscal y social del Antiguo Régimen, no hizo más que resquebrajarse al juntarse el fraude de los labradores con la ofensiva fiscal de la Real Hacienda. La sequía del ingreso tradicional repercutió en la universidad española durante un largo período, influyendo seguramente en el conocido retraso científico.

2) Pasar del diezmo al presupuesto fue la clave de la reforma universitaria liberal, igual que, en cierto modo, lo fue de la reforma agraria; el cambio en la financiación, junto con la reorganización administrativa y académica, alteró radicalmente aquella universidad que hundía sus raíces en la Edad Media. La ruptura con el ordenamiento tradicional, innegable, se combinó con una lógica de inclusión al utilizar lo que quedaba de los diezmos, junto con los ingresos patrimoniales, para financiar la enseñanza durante buena parte del siglo XIX. En este aspecto la sombra del Antiguo Régimen seguía siendo alargada.

3) La reforma universitaria liberal tuvo entre sus objetivos el de eliminar la autonomía financiera de las universidades del Antiguo Régimen, acompañando la centralización académica con la de sus ingresos tradicionales, pero, sobre todo, recurriendo a las tasas académicas ${ }^{48}$; de este modo la universidad podía autofinanciarse en su mayor parte, como ocurría con la enseñanza secundaria y la técnica (Cuadro 6). Todo ello obliga, pues, a tener en cuenta los gastos netos del Estado en la universidad, es decir, los gastos brutos (que son los que hasta ahora se han considerado) menos las transferencias de la universidad al Tesoro. Al ser más bien escasa la aportación neta del Estado, difícilmente pudo ello causar un sistema educativo desequilibrado, no siendo infrecuente que el patrimonio universitario, heredado del Antiguo Régimen, financiara no sólo parte de los estudios superiores sino otros gastos.

48 Todavía en 1910, más de tres cuartas partes del gasto de las facultades provenían de las tasas académicas; años después, este porcentaje se seguía manteniendo en la universidad salmantina. 
4) La centralización liberal no fue completa pues, desde la Revolución de 1868, se implantó en varias universidades un sistema mixto de financiación que permitió la coexistencia de facultades oficiales con facultades libres, de titularidad pública pero costeadas por diputaciones o ayuntamientos; algunas tuvieron una existencia efímera, pero, en diversas provincias, las haciendas locales y provinciales, (muestra del capital social local, podría decirse), se movilizaron para seguir financiando hasta principios del siglo XX enseñanzas, por lo general, de carácter experimental, a donde no llegaba el Estado seguramente por el esfuerzo presupuestario que suponían.

5) Los liberales crearon barreras de entrada eficientes en el acceso a la enseñanza superior; el número de universidades se redujo a la mitad y el de alumnos lo hizo en cerca del 60 por 100, si comparamos la matrícula de mediados del siglo XIX con los datos del Censo de Godoy (Cuadro 9). No volvió a darse una tasa de escolarización como la de 1797 hasta 1924-28, por efecto entonces de una elevada matrícula de alumnos libres, volviendo a bajar en años siguientes. Junto a las variaciones cuantitativas, lo hicieron las características del alumno, variando su sociología. Al acabar los liberales con la gratuidad de la enseñanza superior, cerraron uno de los caminos tradicionales de promoción social; por esta causa desapareció uno de los mecanismos que podían amortiguar la desigualdad de la renta, y la universidad sin duda se hizo más elitista.

6) No era el universitario el nivel educativo que consumía más recursos en España pues, hasta fines del siglo XIX, cuando lo permiten las fuentes, la estructura del gasto educativo a cargo de las administraciones públicas demuestra más bien lo contrario: la enseñanza universitaria (incluida la profesional, técnica y especial) estuvo a menudo por debajo del 20 por 100 (Cuadro 7); esta conclusión obliga a seguir valorando el papel de las otras haciendas, la provincial y municipal.

7) La idea de que el gasto público educativo sesgado a favor de la universidad fuera mayor que en otros países pierde verosimilitud, si se acepta la hipótesis de un mayor grado de autofinanciamiento en España, y si se tiene en cuenta el gasto por alumno. Argumentos complementarios, que hacen mirar con menos optimismo el gasto público en la universidad española, son el elevado número de alumnos matriculados en Derecho, la importancia de los alumnos libres, pero, sobre todo, el raquitismo inversor en las carreras "científicas", lo que en conjunto remite a la miseria del gasto público en enseñanza, algo que se empezó a corregir en parte en el siglo XX.

El inconveniente principal, en definitiva, no estaba en cómo se repartía entre los distintos niveles el presupuesto que iba a enseñanza, o en que el gasto en enseñanza superior - por algún tipo de discriminación positiva en favor de las élites- pudiera influir en el menor gasto de la enseñanza primaria. En mi opinión, no había un problema de "competencia entre estudios superiores y de primaria 
por unos recursos escasos" (Núñez, 1992, p. 317); el problema seguía estando en la "mezquindad", es decir, en que durante muchos años, hasta 1876, no llegaba al 1 por 100 del total lo destinado a la enseñanza, diez o doce veces menos de lo que recibía la Iglesia. Y algo parecido ocurre si se contrasta con otras partidas del presupuesto, por ejemplo las dedicadas al ejército y fuerzas de orden público, comparación que llevó a Fernando de los Ríos a exclamar que "esto es una confirmación más de que aquí vivimos en un Estado policía, pero no en un Estado que tenga conciencia de su cultura" ${ }^{\prime 9}$. Más que Alma Mater, la universidad española se comportó a menudo como arida nutrix ${ }^{50}$.

\section{Fuentes}

Archivo de la Universidad de Salamanca

Libro(s) de Cuentas, 1.464-1.497 (1780-1840); Libro(s) de Claustros, leg. 250-267;

Borrador(es) de Claustros, (1792-1845); Junta de Hacienda, 25-VI-1836, leg. 2.894.

Archivo Central. D1 (4) 6/1, D1 (7) 439/1, leg. 4006.

Archivo Catedralicio de Salamanca

Caja 43 , leg. $2, \mathrm{n}^{\mathrm{o}} 4$.

Archivo Diocesano de Ciudad Rodrigo

Hinojosa, 130.

\section{Bibliografía}

ÁLVAREZ MORALES, Antonio (1974): Génesis de la universidad española contemporánea, Madrid, Instituto de Estudios Administrativos.

Anuario de Instrucción Pública (1889-1892).

Anuario(s) de la Universidad de Salamanca (1864-1927).

Anuario(s) Estadístico(s) de España (1857-68; 1914-27).

Anuario(s) Estadístico(s) de la Instrucción Pública (1901, 1912).

Annuaire International de L'Education et de L'Enseignement (1934), Genève, Bureau International d'Education.

BALDÓ, Marc, y MIR, Vicente (2000): “De Isabel II a Alfonso XIII” en M. Peset, (coord.), Historia de la Universidad de Valencia, vol. III, Universidad de Valencia, pp. 15-28.

\footnotetext{
49 Diarios de Sesiones de las Cortes, 1919-1920, citado en Comín (1988), II, p. 764.

50 La expresión arida nutrix (ama o nodriza seca), que contrapongo a la de "madre nutriente", procede de Horacio (Odas, I. 22.16), referencia que debo a Carlos Fernández Corte.
} 
BLASCO GIL, Yolanda (2000): La facultad de Derecho de Valencia durante la Restauración (1875-1900), Valencia, Universitat de València.

Boletín Oficial de Instrucción Pública (1841), Madrid, Imprenta Nacional.

Boletín Oficial del Ministerio de Comercio, Instrucción Pública (1848).

CANALES, Esteban (1985): “Diezmos y revolución burguesa en España” en GARCÍA SANZ, Ángel y GARRABOU, Ramón (eds.), Historia agraria de la España contemporánea. I. Cambio social y nuevas formas de propiedad (1800-1850), Barcelona, Crítica, pp. 244-274.

CARRACIDO, José R. (1917): Estudios históricos-críticos de la ciencia española, Madrid, Imprenta de "Alrededor del Mundo", $2^{\mathrm{a}}$ ed.

Censo de la población de España en el año de 1797 (Censo de Godoy), Madrid, INE.

Colección Legislativa de España, (1850, 1851, 1854, 1861), tomos XLVII, LIII, LX y LXXV, Madrid, Imprenta Nacional.

Colección de los Decretos y Órdenes generales expedidos por las Cortes desde $1^{\circ}$ de Marzo a 30 de Junio de 1822, Madrid.

Colección de las leyes, decretos y declaraciones de las Cortes, y de los reales decretos (...), Madrid, Imprenta Nacional.

COMÍN, Francisco (1988): Hacienda y economía en la España contemporánea (1800-1936), Madrid, Instituto de Estudios Fiscales.

-(1996): Historia de la Hacienda pública, II. España (1808-1995), Barcelona, Crítica.

CONGRESO INTERNACIONAL DE LAS UNIVERSIDADES HISPÁNICAS (1998):

Doctores y escolares. II Congreso Internacional de las Universidades Hispánicas. Valencia 1995, Universitat de València.

CONSEJO ECONÓMICO Y SOCIAL (2002): Memoria 2001, Madrid, CES.

Datos básicos para la historia financiera de España, 1850-1975 (1976), Madrid, Instituto de Estudios Fiscales.

DÁVILA, Rosa (1992): La Universidad de Valladolid y su hacienda en la transición al régimen liberal, Valladolid, Universidad de Valladolid.

DIRECCIÓN GENERAL DEL INSTITUTO GEOGRÁFICO Y ESTADÍSTICO (1888): Reseña Geográfica y Estadística de España, Madrid, Imprenta de la Dirección General del I.G.E.

FERNÁNDEZ ÁLVAREZ, Manuel, ROBLES, Laureano, RODRÍGUEZ SAN PEDRO, Luis Enrique (eds.), (1989): La Universidad de Salamanca. I. Historia y proyecciones, Salamanca, Universidad de Salamanca.

FLORA, Peter (1983): State, Economy, and Society in Western Europe 1815-1975, Vol. I., Frankfurt, Campus Verlag.

FONTANA, Josep (2001): La Revolución liberal. (Política y Hacienda 1833-45), Madrid, I.E.F. ( $2^{\mathrm{a}}$ ed.).

Gaceta de Madrid, n 24, 23-II-1833.

GARRABOU, Ramón, TELLO, Enric, y ROCA, Albert (1999): “Preus del blat i salaris 
agrícoles a Catalunya (1720-1936)", en Doctor Jordi Nadal. La industrialització $i$ el desenvolupament económic d'Espanya. Barcelona, Universitat de Barcelona, I, pp. 422-460.

GIL DE ZÁRATE, Antonio (1855): De la Instrucción Pública en España, Madrid, Imprenta del Colegio de Sordomudos.

GROIZARD, C. (1899): La instrucción pública en España, Salamanca, Establecimiento Tipográfico de R. Esteban.

IZQUIERDO GÓMEZ, Juan Antonio (1917): Discurso leído en la solemne apertura de estudios del año académico de 1917 a 1918 en la Universidad Literaria de Valencia. Valencia, Tipografía Moderna.

LA FUENTE, Vicente de (1884-1889): Historia de la Universidades, colegios y demás establecimientos de enseñanza en España, Madrid, 4 vols.

LLOPIS, Enrique (2002): “La crisis del Antiguo Régimen y la revolución liberal", en COMIN, Francisco, LLOPIS, Enrique, HERNÁNDEZ, Mauro (eds.), Historia económica de España, Siglos X-XX. Barcelona, Crítica, pp. 121-164.

MACÍAS PICAVEA, Ricardo (1899): El problema nacional, Madrid, Edición de 1992, Fundación Banco Exterior.

MADOZ, Pascual (1835): Reseña sobre el clero y examen de la naturaleza de los bienes eclesiásticos, Barcelona, Imprenta de J. Tauló.

MALUQUER, Jordi (2004): Índice de precios de consumo de España (1831-1931), Madrid, Banco de España (en curso de publicación).

MARTÍNEZ ALCUBILLA, Marcelo (1887): Diccionario de la Administración Española, Madrid, Administración Arco de Santo María, $4^{a}$ ed.

MARTÍNEZ RODRÍGUEZ, Enrique (1981): La Universidad de Santiago de Compostela al final de la época autonómica. Universidad de Santiago.

MINISTERIO DE INTRUCCIÓN PÚBLICA (1910): Memoria elevada a las Cortes por el Excmo. Sr. Ministro de Instrucción Pública, Madrid, Establecimiento Tipográfico y Editorial.

MITCHELL, B. R. (2003): International Historical Statistics. Europe, 1750-2000, London, Macmillan.

MURUA y VALERDI, Agustín (1915): Sobre deficiencias de nuestras Universidades. Sus causas y sus posibles remedios, Madrid, Imprenta de R. Velasco.

MUSEO PEDAGÓGICO NACIONAL (1919a): Las universidades y la enseñanza superior en Francia, Madrid, Cosano.

MUSEO PEDAGÓGICO NACIONAL (1919b): Las universidades en Alemania, Madrid, Cosano.

MUSEO PEDAGÓGICO NACIONAL (1919c): Las universidades, la enseñanza superior y las profesiones en Inglaterra, Madrid, Cosano.

NICOLAU Roser (1989): "Población" en CARRERAS, Albert (coord.), Estadísticas históricas de España, siglos XIX-XX, Madrid, Fundación Banco Exterior, pp. 49-90. 
NÚÑNZ, Clara Eugenia (1992): La fuente de la riqueza. Educación y desarrollo económico en la España contemporánea, Madrid, Alianza.

NÚÑEZ, Clara Eugenia y TORTELLA, Gabriel (eds.), (1993): La maldición divina. Ignorancia y atraso en perspectiva histórica, Madrid, Alianza.

OFFICER, L. H. (2002): "Exchange rate between the United States dollar and forty other countries, 1913-1999", Economic History Services, EH.Net.

PÉREZ MELERO, Joaquín (1999): “Ciencia, tecnología y universidad en el siglo XIX. La Facultad libre de Ciencias de la Universidad de Salamanca (1875-1902)", Historia de la Educación, 18, pp. 241-266.

PÉREZ MOREDA, Vicente (2003): “El cambio demográfico"en ROBLEDO, Ricardo, CASTELLS, Irene, y ROMEO, Ma Cruz (eds.), Orígenes del liberalismo. Universidad, Política, Economía. Salamanca, Universidad de Salamanca, Junta de Castilla y León, pp. 313-317.

PESET, José Luis, y PESET, Mariano (1974): La Universidad española (siglos XVIII-XIX). Despotismo ilustrado y revolución liberal, Madrid, Taurus.

-(1979): “Los gastos públicos de enseñanza en España (1842-1875). Una rectificación de datos anteriores", Hispania, no 143, pp. 671-683.

PESET, José Luis, HERNÁNDEZ SANDOICA, Elena (1994): “Instituciones científicas y educativas" en LAÍN ENTRALGO, Pedro, Historia de España Menéndez Pidal. Tomo XXXX, Vol. II. Madrid, Espasa-Calpe, pp. 547-579.

PIERNAS HURTADO, José Manuel (1885): Tratado de Hacienda Pública y examen de la Española, Madrid, Tipografía de Manuel Ginés Hernández.

POLO, Juan Luis (1995): La universidad salmantina del Antiguo Régimen, 1700-1750, Salamanca, Universidad de Salamanca, 1995.

PRADOS DE LA ESCOSURA, Leandro (2004): El progreso económico de España (18502000), Madrid, Fundación BBV.

RIERA, Santiago (1993): "Industrialization and technical education in Spain, 18501914" en FOX, Robert, GUAGNINI, Anna (eds.), Education, technology and industrial perfomance in Europe, 1850-1939, Cambridge, Cambridge University Press, pp.141-170

ROBLEDO, Ricardo (1991): "El crédito y los privilegiados en la crisis del antiguo régimen", en YUN, Bartolomé, coord., Estudios sobre capitalismo agrario, crédito e industria en Castilla, siglos XIX y XX, Valladolid, Junta de Castilla y León, pp. 237-266.

-(2002): "Quiebra de la Universidad tradicional (1790-1845). Hacienda y Política" en RODRÍGUEZ-SAN PEDRO, Luis Enrique (dir.), Historia de la Universidad de Salamanca. Tomo I. Trayectoria y vinculaciones, Salamanca, Ediciones Universidad de Salamanca, pp. 205-237.

ROBLEDO, Ricardo, CASTELLS, Irene, y ROMEO, Ma Cruz, eds. (2003): Orígenes del liberalismo. Universidad, Política, Economía. Salamanca, Universidad de Salamanca, Junta de Castilla y León. 
ROBLEDO, Ricardo, e INFANTE, Javier (2004): “Declive y recuperación de la Hacienda, 1840-2001" en RODRÍGUEZ-SAN PEDRO, Luis Enrique (dir.), Historia de la Universidad de Salamanca. Tomo II. Estructuras y flujos, Salamanca, Ediciones Universidad de Salamanca, pp. 331-372.

RODRÍGUEZ-SAN PEDRO, Luis Enrique (1994): “Estructuras económicas y financiación de las Universidades españolas en la Edad Moderna", Studia Historica. Historia Moderna, XII, pp. 189-204.

RODRÍGUEZ-SAN PEDRO; Luis Enrique (ed.), (2000): Las Universidades Hispánicas: de la Monarquía de los Austrias al centralismo liberal. V Congreso Internacional sobre Historia de las Universidades Hispánicas. Salamanca 1998, Tomo II, Salamanca, Junta de Castilla y León.

RODRÍGUEZ-SAN PEDRO, Luis Enrique (dir.), (2002): Historia de la Universidad de Salamanca. Tomo I. Trayectoria y vinculaciones, Salamanca, Ediciones Universidad de Salamanca.

-(2004): Historia de la Universidad de Salamanca. Tomo II. Estructurasy flujos, Salamanca, Ediciones Universidad de Salamanca.

SALCEDO, E. (1998): Vida de Don Miguel (Unamuno, un hombre en lucha con su leyenda), Salamanca, Anthema.

SÁNCHEZ GRANJEL, Luis (1989): La Facultad libre de Medicina de Salamanca, 18681903, Salamanca, Centro de Estudios Salmantinos.

SÁNCHEZ RON, José Manuel (1999): Cincel, martillo y piedra. Historia de la ciencia en España (siglos XIX-XX), Madrid, Taurus.

SIMÓN SEGURA, Francisco (1973): La desamortización española del siglo XIX, Madrid, I.E.F. TEDDE, Pedro (1985): “El gasto público en España, 1875-1906: un análisis comparativo con las economías europeas", en MARTÍN ACEÑA, Pablo, PRADOS DE LA ESCOSURA, Leandro (eds.), La nueva historia económica de España, Madrid, Tecnos, pp. 233-261.

TERRÓN, Aida (2000): "El ideario y las realizaciones pedagógicas del Grupo de Oviedo", en URÍA, Jorge (coord.), Institucionismo y reforma social en España, Madrid, Talasa.

TORTELLA, Gabriel (1995): El desarrollo de la España contemporánea, Madrid, Alianza.

UNIVERSIDAD LITERARIA DE SALAMANCA: Memoria(s) sobre el estado de la Enseñanza en la ... y estado de la Instrucción Pública. Salamanca.

VIDAL, Alejandro (1869): Memoria histórica de la Universidad de Salamanca, Salamanca, Imprenta Oliva.

VILAR, Pierre (1964): Crecimiento y desarrollo. Economía e historia. Reflexiones sobre el caso español, Barcelona, Ariel.

VV AA (1989): Historia de la Universidad de Valladolid, Valladolid, Universidad de Valladolid.

VV AA (2003): Aulas y saberes. VI Congreso Internacional de Historia de las Universidades Hispánicas (Valencia, diciembre 1999), Vol. I, pp. 71-84.

ZAMAGNI, Vera (1993): “Instrucción y desarrollo económico en Italia, 1861-1913", en NÚÑEZ, Clara Eugenia, TORTELLA, Gabriel (eds.), La maldición divina. Ignorancia y atraso en perspectiva histórica, Madrid, Alianza, pp. 181-222. 